\title{
PRIMARY TEACHERS' PERCEPTIONS OF MINDFULNESS PRACTICES WITH YOUNG CHILDREN
}

\author{
By
}

Stephanie Anne Piotrowski

Bachelor of Arts, Early Childhood Studies, Ryerson University, 2013

Bachelor of Education, University of Ottawa, 2014

\author{
A Major Research Paper \\ Presented to Ryerson University \\ in partial fulfillment of the requirements for the degree of \\ Master of Arts \\ in the Program of \\ Early Childhood Studies
}

Toronto, Ontario, Canada, 2015

(C) Stephanie Anne Piotrowski, 2015 


\section{Author's Declaration}

I hereby declare that I am the sole author of this MRP. This is a true copy of the MRP, including any required final revisions.

I authorize Ryerson University to lend this MRP to other institutions or individuals for the purpose of scholarly research.

I further authorize Ryerson University to reproduce this MRP by photocopying or by other means, in total or in part, at the request of other institutions or individuals for the purpose of scholarly research.

I understand that my MRP may be made electronically available to the public. 


\begin{abstract}
Primary Teachers’ Perceptions of Mindfulness Practices with Young Children
\end{abstract}

Master of Arts, 2015

Stephanie Anne Piotrowski

Program of Early Childhood Studies, Ryerson University

This qualitative descriptive study aimed to present findings from four primary teachers and their perceptions of mindfulness practices with young children. Using open-ended and semi-structured interviews, these teachers in the school system shared their experiences with mindfulness practices in their classrooms. This study, using a thematic analysis, indicated that teachers felt there to be benefits of including mindfulness practices in their classrooms but have found that there are various issues that may hinder successful implementation. Integrating different mindfulness practices in the classroom could allow childhood well-being to be improved though holistic approaches.

Key Words: mindfulness, meditation, children, loving-kindness, education 


\section{Acknowledgements}

I would like to thank my supervisor, Dr. Marni Binder, for her endless support and encouragement throughout this process of writing this major research paper. Thank you for the invaluable feedback you have provided me, pushing me to leave my comfort zone, and take risks. I would also like to thank Dr. Jasna Schwind for being my second reader and for providing me with feedback and suggestions to further enhance my research. Thank you for providing me insight into a different side of mindfulness outside of the educational system and introducing me to new forms of qualitative study. To Dr. Kathleen Peets, thank you for taking the time to chair my defence.

I would like to thank Dr. Jessica Whitley who introduced me to mindfulness practices during my Bachelor of Education degree. It was such a life-changing experience to facilitate mindfulness practices with my classmates in the 2013-2014 Comprehensive School Health Cohort.

I would also like to thank the four teachers who took the time out of their busy schedules to meet with me. I truly enjoyed hearing about your experiences. Your passion for implementing mindfulness into your classroom inspires me to use these practices with children in the future.

Lastly, I would like to thank all of the lovely ladies and faculty in the Early Childhood Studies program. I am so glad to have met such a wonderful group of women who are so kind and inspiring. I wish you all of the best in your personal, academic, and career endeavours and I hope to stay in touch. Good luck! 


\section{Dedications}

"If a cluttered desk is a sign of a cluttered mind, of what, then, is an empty desk a sign?" - Albert Einstein

I would like to dedicate this Major Research Paper to my family. Thank you for supporting me throughout this process and allowing me to turn the dining room table into my own little office space. Your words of encouragement, help with editing, and endless supply of espresso helped me to finish this paper.

To Anthony, thank you for supporting me throughout this process and reminding me that I can accomplish what I set out to do. You have believed in me from the beginning and have pushed me to succeed. Thank you for being my study buddy, keeping me sane, and making me laugh. 


\section{Table of Contents}

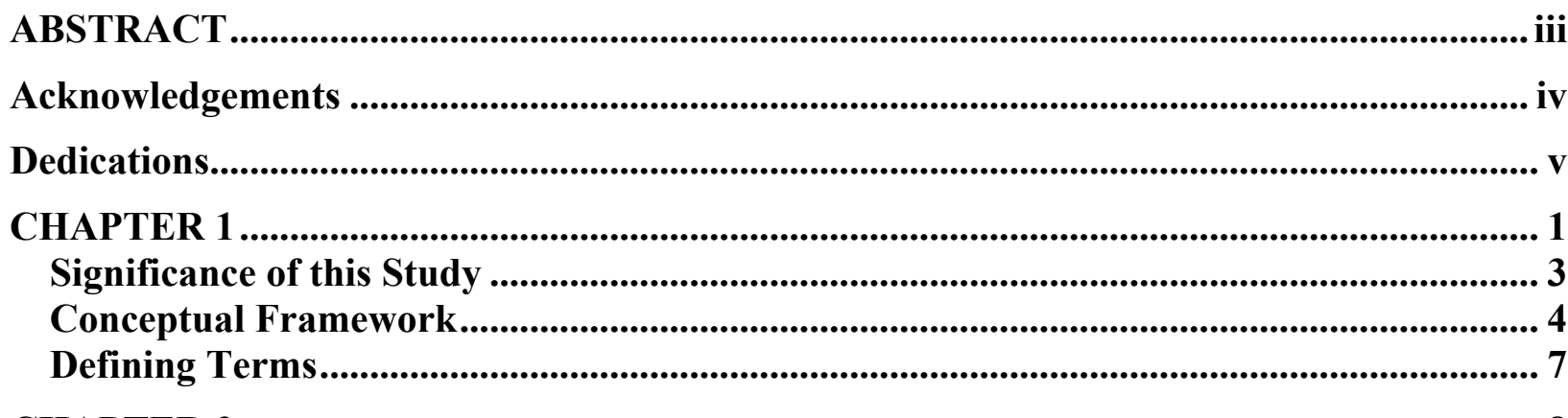

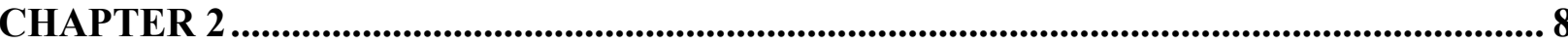

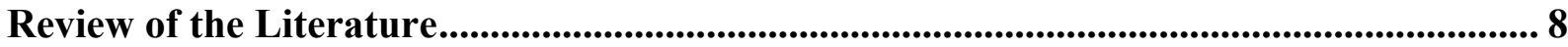

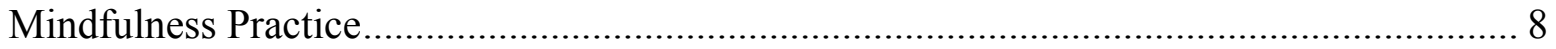

Mindfulness-Based Stress Reduction (MBSR) Program ................................................ 11

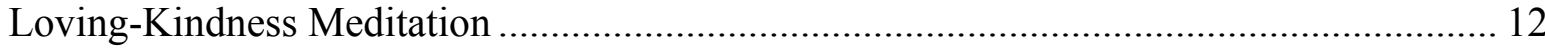

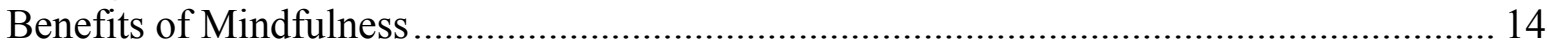

Challenges Associated with Mindfulness Practices................................................... 17

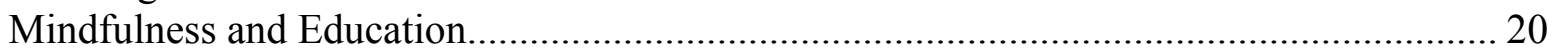

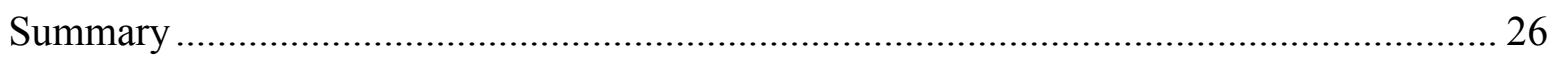

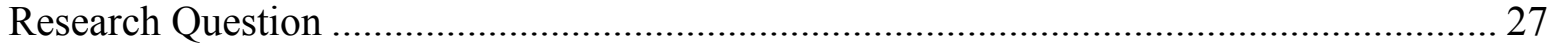

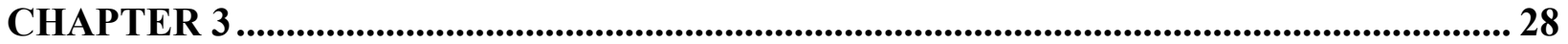

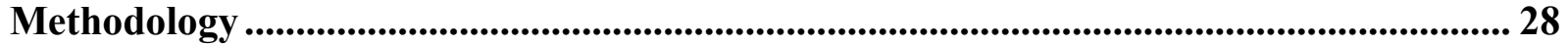

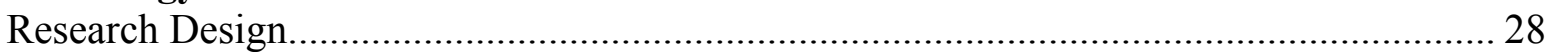

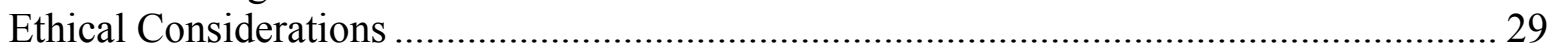

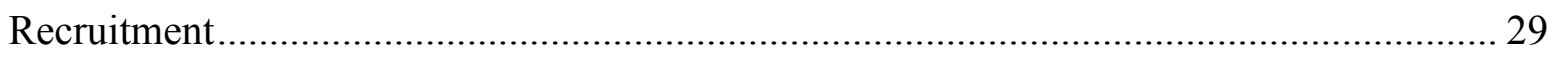

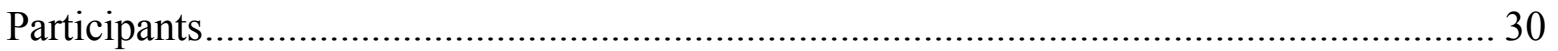

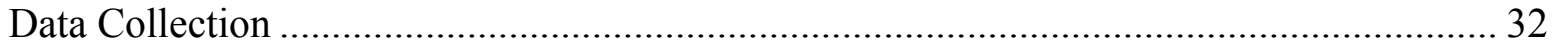

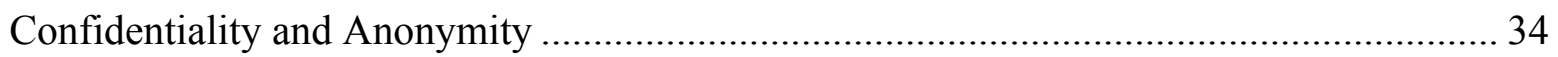

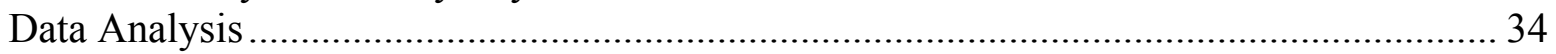

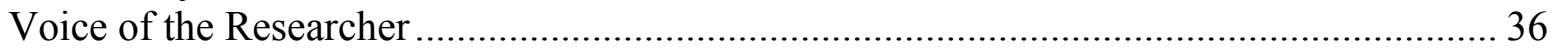

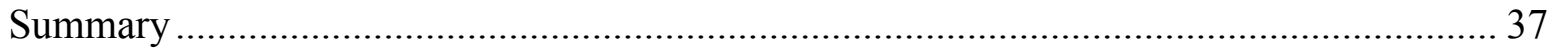

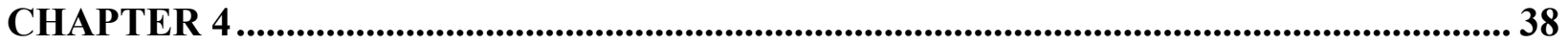

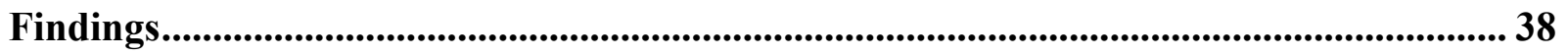

Practices Used in the Classroom .......................................................................... 41

Benefits of Mindfulness Practices with Children ......................................................... 45

Challenges for the Implementation of Mindfulness Practices ...................................... 51

CHAPTER 5

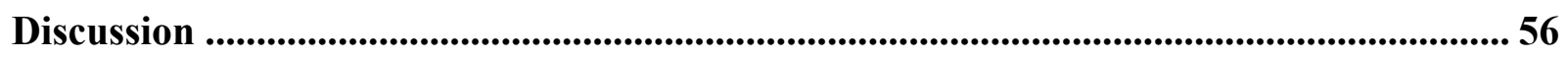

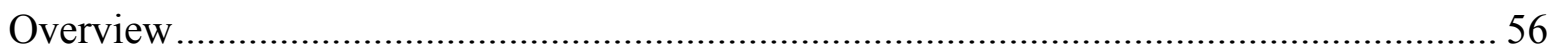

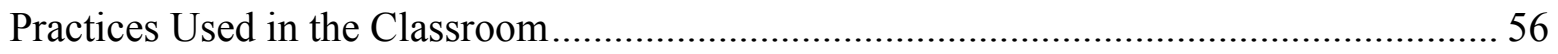


Benefits of Mindfulness in the Classroom................................................................ 58

Challenges Associated with Mindfulness in the Classroom .......................................... 59

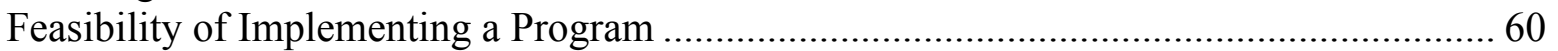

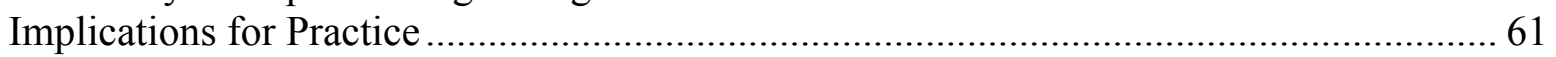

Limitations to the Study and Directions for Further Research ...................................... 62

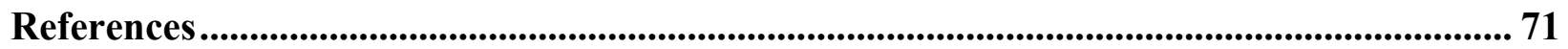




\section{List of Appendices}

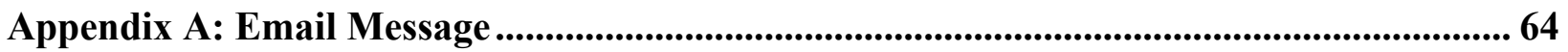

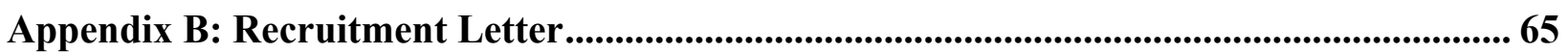

Appendix C: Consent Letter ................................................................................................................ 66

Appendix D: Interview Guide......................................................................................................... 70 


\section{CHAPTER 1}

\section{Introduction}

Peace is present right here and now, in ourselves and in everything we do and see. The question is whether or not we are in touch with it. We don't have to travel far away to enjoy the blue sky. We don't have to leave our city or even our neighborhood to enjoy the eyes of a beautiful child. Even the air we breathe can be a source of joy.

$$
\text { Hạnh, 1992, p. } 5
$$

My first experience with mindfulness practices occurred at the end of my Bachelor of Education degree. When enrolled in this program I was a part of the Comprehensive School Health cohort. In each of the classes, we discussed various ways in which the curriculum could be adapted to foster healthy living, healthy relationships, and healthy environments. One of the faculty members had invited our cohort to volunteer in a nearby school to practice mindfulness with the children. I had no prior experience with mindfulness and was very interested in learning more about it. I attended the information session and was intrigued at how the practices were modified for young children and how we, as students could benefit from participating. For approximately four months two classmates and I volunteered weekly, facilitating mindfulness practices with kindergarten students. For two months we practiced with the junior kindergarten students and the remaining two months were spent with the senior kindergarten students. Through the mindfulness practices and discussions with the teachers and students, it appeared that these young children were starting to grasp ideas about being aware of their actions throughout the day and focusing on their breathing. The classroom teacher and early childhood educator spoke about their efforts to integrate mindfulness into the classroom activities and felt that the children were responding well. The kindergarten teacher and early childhood educator talked about how they perceived children to be more attentive in daily activities and instances of 
anxiety lessened. My participation in this volunteer experience has prompted me to learn more about different types of mindfulness practices being used in the classroom and whether or not teachers find it useful.

In Canada, it is estimated that one in seven children aged four to seventeen are experiencing symptoms related to mental health disorders such as stress and anxiety, which affect their livelihood at home and in the school environment (Waddell, 2007). Research has found that children who are stressed often display acts of anger and depression, which can result in lowered self-esteem and self-confidence (Rempel, 2012). These mental health issues affect children's overall well-being and their ability to flourish in the classroom environment, as they may not be able to focus on the task at hand and are unable to foster positive social-emotional relationships with themselves and their peers (Rempel, 2012; Waddell, 2007). Since children spend much of their day in the classroom, teachers have been encouraged to find ways to nurture well-being in the learning environment (Rempel, 2012).

Research suggests that the implementation and practice of a mindfulness program in the classroom helps to reduce stress, anxiety, and improve executive functioning which are the processes needed for working memory, response inhibition and the ability to plan and carry out an activity with a purpose (Anand \& Sharma, 2014; Benn et al., 2012; Biegel et al., 2009; Flook et al., 2010; Morone et al., 2012; Van Dam et al., 2014). Teachers view that a mindfulness-based program implemented into their classroom has been beneficial for their students and is effective in creating a sense of cohesiveness along with motivating students to find their potential to succeed (Schonert-Reichl \& Lawlor 2010). Young children can benefit from these practices because it allows for the opportunity to learn in an environment that is creative and sensitive to their needs (Capel, 2012). Incorporating creative elements into the classroom is important, as 
children are given different opportunities for learning (Capel, 2012). When children feel their needs are being met in different ways, their self-esteem and overall well-being will also improve (Capel, 2012).

\section{Significance of this Study}

The purpose of this research is to explore teachers' perceptions of mindfulness practices with young children in their classrooms. Most of the research (Britton et al., 2014; Flook et al., 2010; Flook et al., 2015; Fredrickson et al., 2008; Liehr \& Diaz, 2010; Weijer-Bergsma et al., 2014) involved participants divided into mindfulness intervention and waitlist control groups with researchers implementing mindfulness practices and evaluating them after an intervention period. The teachers who took part in this research have implemented mindfulness practices throughout the year by embedding them in their curriculum and have been able to discuss the changes they have noticed in their classroom over a longer period of time. In this study, by allowing teachers the opportunity to describe their experiences of integrating mindfulness practices, will provide insight into how primary teachers could implement this practice on a regular basis in their classrooms.

Data was collected through the use of one-on-one interviews. The conceptual framework that informed this study was of a holistic perspective, which looks at the connection between various areas of an individual - their mind, body, and spirit (J. Miller, 2007). The results from this research would be valuable for professionals working with children who may have heard about mindfulness practices and its use in the classroom. This research could spark teacher interest in learning about mindfulness and further investigating the ways in which it can be implemented into the classroom and into their personal lives. 


\section{Conceptual Framework}

This research is framed by a holistic philosophy as it explores the connection between the mind, body, and spirit (J. Miller, 2007). Mindfulness is deeply rooted in a philosophy that encompasses the person as a whole being. The concept of holism comes from the Greek word, holon, meaning that the "universe is made up of integrate wholes that cannot simply be reduced to the sum of its parts," (J. Miller, 2007, p.6). Frances Vaughan (1979) describes the connection between holistic education and intuition (as cited in J. Miller, 2007). Intuition is described as “direct knowing” (J. Miller, 2007, p. 90). He states that humans have four levels of intuition, "physical, emotional, mental, and spiritual" (J. Miller, 2007, p. 91). The application of a holistic framework in early childhood education emerged from theorists such as Jean Jacques Rousseau, Maria Montessori, Friedrich Froebel, Johann Heinrich Pestalozzi, Rudolf Steiner, and John Dewey (Campbell, 2011; J. Miller, 2011; R. Miller, 1991; R. Miller, 2000; Taggart, 2001). Rousseau and Montessori followed an approach that involves acknowledging the soul of the child and providing an environment that allows for children to construct knowledge in a way that naturally occurs with development (Mahmoudi, Jafari, Nasrabadi, \& Liaghatdar, 2012). This type of environment would provide students with the support needed to learn without being pressured by educators (Mahmoudi et al., 2012). Pestalozzi stressed the importance of respecting the individuality of each child and developing their different types of intelligence in various domains (J. Miller, 2011) such as arts, sciences, and mathematics. Froebel took a different approach to holistic education by trying to preserve the goodness of the child and fostering development through play (J. Miller, 2007). Steiner created a system called "Anthroposophy" which looked at the integration of spiritual elements in human beings (R. Miller, 1991, p. 57). He describes the spiritual world as being intertwined into the physical world (Uhrmacher, 1995). 
The mind and body cannot be separated thus experience can be felt in both the mind and in a physical way (Uhrmacher, 1995). Lastly, Dewey had ideologies in holistic education as he believed in the importance of integrating practical with theoretical knowledge (Taggart, 2001).

The implementation of a holistic educational practice has been made known through current leaders Ron Miller (1991; 2000) and John P. Miller (2006; 2007; 2014). Ron Miller (2000) stressed the significance of the "underlying unity connecting everything in the universe mind and matter, humanity and nature, life and physical laws, and every person with every other, across all artificial distinctions" (p. 384). His work repeatedly discusses the connections that must be made to spirituality in order to develop authentic meaning from everyday events ( $R$. Miller, 2000). These connections can be made by becoming aware of how everyday events are an "intricate web of experiential, social, physical, and spiritual connections" which helps to bring spirituality to the forefront (R. Miller, 2000, p. 384). He noted the basic principles he believed employ a holistic approach in the classroom. Ron Miller (2000) stated that a classroom that follows a holistic perspective educates the child as a whole person and fosters their need to explore and experiment with their surrounding environment. The focus is on the experience rather than educating the child to develop an academic set of skills or knowledge (R. Miller, 1990a as cited in R. Miller, 2000). He suggests that teachers create a classroom environment that is natural, creative, and spontaneous in nature (R. Miller, 2000). When an environment is natural, the focus is more on an active engagement and the process of learning itself rather than concentrating on a particular desired outcome (R. Miller, 2000). Ron Miller (2000) believes that there are five different components that are essential for holistic education to be successful (as cited in Mahmoudi et al., 2012). Firstly, there must be an acknowledgment of the physical, emotional, intellectual, social, aesthetic, and spiritual components that makes a person whole (R. 
Miller, 2000 as cited in Mahmoudi et al., 2012). Additional components of holistic education extend from the whole person towards making relationships with the "community, society, planet, and the cosmos" (R. Miller, 2000 as cited in Mahmoudi et al., 2012, p. 182-183). The cosmos is described as "the primary whole, the complete context that gives meaning to our being - the spiritual dimension of human existence" (Mahmoudi et al., 2012, p. 183).

John P. Miller (2007) contributes significantly to the field of holistic education. He talks about how "balance, inclusion, and connection" are the foundational principles of holistic education (p. 6). He describes balance as the acknowledgement of interconnected energies (J. Miller, 2007). He makes reference to the yin/yang in Taoism and the ways in which it can be applied to the educational setting (J. Miller, 2007). For example, the yang energy would value individualist thinking as well as having a focus on knowledge and assessment strategies, whereas the yin would create a classroom based on imagination, learning, and group collaboration ( $\mathrm{J}$. Miller, 2007). A classroom that is based on holistic practices would integrate both types of energies in order for students to learn (J. Miller, 2007).

The inclusion principle is comprised of "transmission, transaction, and transformational" forms of teaching and learning (J. Miller, 2007, p. 10). J. Miller (2007) describes transmission as a one way flow of knowledge from the teacher to the student whereas transaction involves a more interactive approach where the teacher and the student are conversing and knowledge is exchanged between both parties. Finally, a transformative approach acknowledges the whole child and uses strategies such as cooperative learning and creative problem solving to educate the child. This approach is transformational because it allows for a continuous dialogue between the teacher and students that is meaningful to the child. Teachers who employ this type of process account for students' individual needs and ensure that the curriculum is connected to the child (J. 
Miller, 2007).

The last component of holistic education involves making connections between the curriculum, the child, and fostering relationships with the mind, body, soul, community, and the earth (J. Miller, 2007). By using strategies that meet the different needs of students allow children to be aware of the different relationships they have with themselves and the world around them while learning the skills needed to nurture these relationships (J. Miller, 2007).

\section{Defining Terms}

Mindfulness. There are many ways to define mindfulness. Thich Nhat Hạnh (1987), a Zen Buddhist monk, describes mindfulness as "keeping one's consciousness alive to the present reality" (p. 11). According to Salzberg (1997), when one is being mindful, one is aware of what is happening in the present moment, without bias and need to want to change the experience. For the purpose of this study, mindfulness will be described according to Kabat-Zinn (2005) who defines mindfulness as "moment-to-moment, non-judgmental awareness, cultivated by paying attention in a specific way, that is in the present moment, and as non-reactively, as nonjudgmentally, and as open-heartedly as possible" (p. 108).

Well-Being. The concept of well-being has been found throughout different disciplines and forms of literature. For example, to some scholars, the concept of well-being is seen as being in the present state, whereas others see it as a work in progress (Amerijcjx \& Humblet, 2014). Well-being is comprised of various categories that include health, purpose, community, environment, and security (Kreitzer, 2012). For this research, well-being is described as "a state of being in balance and alignment in body, mind, and spirit. It is a state in which people describe themselves as feeling healthy, content, purposeful, peaceful, energized, in harmony, happy, prosperous, and safe" (Kreitzer, 2012, p. 707). 


\section{CHAPTER 2}

\section{Review of the Literature}

The purpose of this literature review is to provide a description of the roots of mindfulness, the benefits of the practice, challenges, and connections to the learning environment. The effects of mindfulness on student learning and the importance of personal practice will be noted. Although the literature discusses mindfulness practices and its application to various contexts, this review will focus on the effects of practices primarily in educational settings. This review focuses on the following major themes that emerged throughout the literature: mindfulness practice, Mindfulness-Based Stress Reduction (MBSR) program, LovingKindness meditation, benefits of mindfulness, challenges associated with mindfulness practices, teacher personal practice, and student learning. This literature review used a combination of published books, online publications, as well as peer-reviewed journal articles between the years 2000 and 2015. Earlier literature published in 1987, 1992, and 1998 by Thích Nhất Hạnh and Sharon Salzberg were used to provide a foundational background in this topic.

\section{Mindfulness Practice}

Mindfulness is a practice that has origins in Buddhism but is not religious in nature (Ott, 2004). This is important because many people may be apprehensive about using this practice if they think that it is associated with a religion. For the purpose of this research, I will focus on one main aspect of Buddhism that relates to mindfulness - the breath.

The anchor of mindfulness is in the breath (Hạnh, 1998, Kabat-Zinn, 2011; J. Miller, 2014; Salzberg, 2010). The "breath is the bridge which connects life to consciousness, which unites your body and your thoughts", it is "the means to take hold of your mind again" (Hạnh, 1987, p.15). The breath is an essential component of mindfulness as it allows for the 
strengthening of the lungs, blood, and each organ in the body (Hạnh, 2008). Mindfulness focuses on being attentive to one's own breathing, whether it is calm and harmonious or quick and rushed (Rotne \& Rotne, 2013). When an individual breathes in a slow, attentive, and harmonious way, it positively affects the parasympathetic nervous system, which regulates the body's unconscious actions (Rotne \& Rotne, 2013). This positive affect on the nervous system soothes the body and allows for an inner calmness in the mental, physical, and emotional aspects of the body (Rotne \& Rotne, 2013). This calmness achieved through deep breathing is a direct result of the parasympathetic system releasing a neurotransmitter, acetylcholine, which helps increase feelings of relaxation (Rotne \& Rotne, 2013).

There are many different approaches to mindfulness practices outlined by Thích Nhất Hạnh (1987; 1992; 1998), Sharon Salzberg (1997; 2008; 2010; 2011), Jack Kornfield (2007; $2010 ; 2012)$, and Jon Kabat-Zinn $(2003 ; 2009 ; 2011 ; 2013)$ who are leaders in the mindfulness movement. Thích Nhất Hạnh, a Buddhist monk, describes mindfulness as a practice which allows one to live a life of awareness (Hạnh, 1987). He believes that the presence of mindfulness in one's life is to be the presence of life itself (Hạnh, 1987). Hạnh (1998) stressed the importance of living a mindful life which includes being mindful of breathing, walking, and every moment throughout the day. The practice of mindfulness involves being mindful of the body, feelings, mind, and phenomena. When being mindful of the body there is an awareness of each body part, its position on the body, and associated movements. Feelings are observed and identified as being pleasant, unpleasant, or neutral (Hạnh, 1998). In order to be mindful of the mind, Hạnh (1998) stated that it is important to be aware of "mental formations" (p. 71). A mental formation is "anything that is 'formed', anything that is made of something else" which can include anger, determination, and perception (Hạnh, 1998, p.73). Hạnh (1998) further described the object that 
is associated with a mental formation as being a person or a thing. By practicing mindfulness on a regular basis, he believes that the "seed of mindfulness" can be nurtured (Hạnh, 1987, p. 187). It is important to "water the seed" through regular mindfulness practice and becoming aware of wisdom that is present within (Hạnh, 1987, p. 238).

Salzberg (1997) views mindfulness as having an awareness of the present moment and acknowledging the experience without bias or judgment. This awareness of the moment is inclusive in nature as an individual who is practicing mindfulness is accepting of all experiences that are occurring in the moment (Salzberg, 1997). Through the act of being mindful, the purpose is to observe the feelings associated with the moment, whether it be of interest, curiosity, compassion, or despair and then let it go and return to the breath as an anchor (Salzberg, 2010). Salzberg $(2008 ; 2011)$ also makes the connection between mindfulness practices and lovingkindness. Practicing mindfulness, allows for a greater connection to the loving-kindness meditation, which results in a sense of balance and serenity (Salzberg, 2011). She stresses the importance of the inclusion of a loving-kindness meditation to allow for the recognition of the interconnected nature of all beings (Salzberg, 2011).

Similar to Salzberg $(1997 ; 2008 ; 2010 ; 2011)$, Kabat-Zinn (2011) views mindfulness as being aware of what arises when one is paying attention in the moment, without judgment, and also puts an emphasis on the breath as being an object that is representative of the present moment. It is important to have a "beginner's mind", an innate ability which allows for openness to new experiences (Kabat-Zinn, 2011, p. 9). He believes that mindfulness is a universal tool that can be cultivated by all beings as attention and awareness are also innate human capacities (Kabat-Zinn, 2011). Even though these abilities are inherent to each individual, effort is required by the individual to overcome barriers such as habitual unawareness and focus on the present 
moment (Kabat-Zinn, 2011).

Kornfield (2008; 2012) agrees with Salzberg (1997) and Kabat-Zinn's (2011) conceptualization of mindfulness being an experience that is non-judging and receptive. Kornfield (2012) further looks at each occurrence as a teaching experience that provides insight into being more present in daily life. In order to demonstrate insight, there are four principles that make up "mindful transformation" - recognition, acceptance, investigation, and nonidentification (Kornfield, 2012, p. 5). A mindful transformation is one in which an individual can be changed by being aware of daily endeavours. When one is displaying actions of recognition and acceptance, an individual has the opportunity to acknowledge the experience and accept the experience for what it is (Kornfield, 2012). Through acts of investigation and nonidentifcation, areas of hardship or truth is recognized and accepted as a part of an experience rather than a personal characteristic (Kornfield, 2012).

\section{Mindfulness-Based Stress Reduction (MBSR) Program}

In 1979, Jon Kabat-Zinn (2003) started the Mindfulness-Based Stress Reduction (MBSR) program at an outpatient stress reduction clinic at the University of Massachusetts Medical Center. Kabat-Zinn's (2003) goal was to create a program that would help patients to address underlying issues that cause stress and introduce strategies to help promote relief. This program adapted to include some of the Buddhist origins of mindfulness while being free of cultural and religious associations (Kabat-Zinn, 2003). The program initiated by Kabat-Zinn was eight weeks long with a total of nine sessions for approximately two and a half hours per week (McCown, Rebel, \& Micozzi, 2010). The MBSR program offered mindfulness practices such as mindful movements, awareness activities, body scan, hatha yoga, and deep breathing along with guidance and different ways to incorporate these practices on a regular basis (Kabat-Zinn, 2003). In this 
program patients learned about their emotions, the significance of stress, and were encouraged to practice the various skills and techniques learnt at home (Bishop, 2002). When participating in a MBSR program, the goal was to be able to respond to various events in one's life mindfully instead of reacting on impulse (Bishop, 2002).

In order to be successful in the MBSR program, Kabat-Zinn (2013) outlined seven attitudinal factors that form the foundational pillars. The pillars: "non-judging, patience, a beginner's mind, trust, non-striving, acceptance, and letting go" is reliant upon and influences each other (Kabat-Zinn, 2013, p. 32). Non-judging and patience involves paying attention to the experience and not judging it while patience involves accepting the life sequence of events unfolding in time (Kabat-Zinn, 2013). The pillar, beginner's mind, is the concept of looking at the world and experiences as if it were the first time. The purpose of trust and non-striving is to trust in one's ability to be yourself. Lastly, acceptance and letting go is the ability to be present in the moment and see things as they are while not forming an attachment to the experience and letting it go (Kabat-Zinn, 2013).

\section{Loving-Kindness Meditation}

Another mindfulness practice discussed in the literature is the loving-kindness meditation (LKM), known in Pali, as metta (Leppma, 2012). Metta is the notion of being related and accepting others throughout the world (Leppma, 2012). The LKM is a type of meditation where individuals nurture and promote positive feelings directed towards themselves, their loved ones on the planet, and to all beings in the universe (Salzberg, 1995 in Leung et al., 2013). It is the recognition that humans are all connected in some way and wish to be happy and healthy (Salzberg, 2011). When engaging in a loving-kindness meditation, the individual is sitting down, eyes closed, focusing on the breath that is entering the body (Leppma, 2012). While focusing on 
the breath, the thoughts of loved ones enter the mind and love, kindness, and acceptance are sent to all the beings in the world (Leppma, 2012). When participating in a loving-kindness meditation, individuals are often letting go of built up feelings and resentment they may have had towards themselves or others (Kabat-Zinn, 2005 in Leppma, 2012).

Studies have found that participating in a short loving-kindness meditation has resulted in positive affective learning, increased positive emotions, and feelings of being more satisfied with their lives (Fredrickson et al., 2008; Hunsinger et al., 2013). Hunsinger et al., (2013) conducted a quantitative study that implemented 20-minute LKM sessions with adults for three days. The measurement SAFCON was used to assess susceptibility to affective conditioning and a Stroop task measured cognitive control (Hunsinger et al., 2013). Findings stated that the degree to which participants associated positive feelings towards neutral stimuli increased after LKM (Hunsinger et al., 2013). These findings are significant as it shows that participants often view neutral situations or images through a positive outlook in comparison to a negative one (Hunsinger et al., 2013). These positive feelings are an early stage of affective learning, which is involved in attitude formation (Hunsinger et al., 2013). Similarly, Fredrickson et al's (2008) quantitative study tested a hypothesis in a field experiment with 139 adult participants divided into LKM and waitlist control groups. Sixty-seven participants in the LKM group meditated for 60 minutes a week over a period of seven weeks (Fredrickson et al., 2008). The first session involved sending love and compassion towards themselves while subsequent weeks built on previous sessions by sending love and compassion to loved ones, acquaintances, strangers, and all living beings (Fredrickson et al., 2008). Using Brown \& Ryan's (2003) Mindfulness and Awareness Scale and other tools such as the Life Orientation Test, and Dyadic Adjustment Scale, it was found that participants had increased positive emotions and overall well-being (Fredrickson et 
al., 2008). It was also found that since participants also practiced LKM on their own for a minimum of five days per week that there was a slight shift in their ability to accept themselves, become more aware of their surroundings, and foster positive relationships with others (Fredrickson et al., 2008).

Leung et al. (2013) created a voxel-based morphometry study to look at the effects of practicing a loving-kindness meditation on the brain. A voxel-based morphometry study is one in which MRI images are taken of the brain and gray matter is looked at. This study looked at 25 men - ten were LKM experts with over five years of practice, and fifteen were novices with seven hours of training. Each participant was of the same age, educational level, and was of good health (Leung et al., 2013). The expert group had a mean age of 50.2, 14 years of education and 6456 meditation hours while the novice group had a mean age of 47.7 and 16.9 years of education (Leung et al., 2013). It was found from high-resolution MRI brain images that those who practiced loving-kindness meditation on a regular basis had significantly more gray matter in their right angular and right posterior parahippocampal gyru of the brain (Leung et al., 2013). The right angular gyrus is a part of the brain that helps to understand thoughts, feelings, and the desires of others (Leung et al., 2013). Whereas the right posterior parahippocampal gyru is a part of the limbic system which allows for the use of higher order cognitive functions in order to help regulate emotions, moods, and demonstrate self-control (Kiehl, 2006 in Leung et al., 2013). Having more gray matter in different parts of the brain signifies that there is higher functioning in those particular areas (Holzel et al., 2011).

\section{Benefits of Mindfulness}

Multiple studies (Anand \& Sharma, 2014, Beauchemin et al., 2008; Biegel et al., 2009; Benn et al., 2012; Coffey et al., 2010; Erisman \& Roemer, 2012; Liehr \& Diaz, 2010; Morone et 
al., 2012; Semple et al., 2015; Van Dam et al., 2014) have been conducted to determine the effects of mindfulness interventions on various groups of people. The research appears to agree that a major benefit of incorporating mindfulness practices is a reduction in anxiety (Anand \& Sharma, 2014, Beauchemin et al., 2008; Biegel et al., 2009; Benn et al., 2012; Liehr \& Diaz, 2010; Morone et al., 2012; Van Dam et al., 2014). In a randomized clinical trial by Biegel et al. (2009), 102 adolescents between the ages of 14-18 years old, who displayed mental health issues, took part in an eight-week MBSR program that occurred once a week for two hours. The sessions focused on informal and formal mindfulness practices such as a sitting, body scan, and walking meditation along with Hatha yoga (Biegel et al., 2009). Sessions focused on issues pertaining to adolescents such as self-image, self-harming behaviours, life transitions, and interpersonal relationships (Biegel et al., 2009). Upon completion of this program, 74 participants who completed all three assessments were found to have a reduction in anxiety and depressive symptoms along with improved self-esteem (Biegel et al., 2009).

Similarly, Anand and Sharma (2014) conducted a mixed method study with 33 adolescents aged 13-15 years old that focused on the feasibility and usefulness of a MBSR program to reduce stress and improve well-being in the school environment. The MBSR program implemented in the school involved eight 40-minute weekly sessions based on the MBSR program by Kabat-Zinn (2003) and a stress reduction workbook for teens created by Biegel et al. (2009) (Anand \& Sharma, 2014). The program focused on learning about stress and used mindfulness practices such as mindful sitting, mindful eating, mindful walking, mindful listening and body scan, and homework assignments (Anand \& Sharma, 2014). It was reported that participants had significant reductions in physiological and academic stress, with an improvement in their overall well-being. Similar to Biegel et al. (2009), the length of this 
program was eight weeks long, however the sessions were shorter, 40 minutes in duration (Anand \& Sharma, 2014).

Practicing mindfulness has also been observed in an open clinical trial by Semple, Reid, and Miller (2015) as a way for children to decrease anxiety and increase their ability to effectively self-cope during troubled times. Semple et al's (2015) trial with five children between the ages of seven to eight years old who displayed various instances of anxious behaviours in the classroom. For six weeks, once per week, these students took part in a 45 minute guided meditation. Upon conclusion of the program and assessment of the children, teachers noted that these students displayed gains in their ability to handle classroom and academic demands and noticed a reduction in problem behaviours (Semple et al., 2015). Notably, four out of the five children stated that they really enjoyed the program and were upset that it did not continue for a longer period of time. These mindfulness practices allowed the children the opportunity to form a stronger relationship and awareness with their own body and mind, which resulted in less stress (Semple et al., 2015).

Having a stronger relationship with one's own body and mind resulting in less stress can help address symptoms of depression and anxiety that many children face. Depression and anxiety are some of the most common mental health problems that children face on a regular basis (Farrell \& Barnett, 2007, as cited in Liehr \& Diaz, 2010). In order to address these issues, Liehr and Diaz's (2010) experimental design assessed two programs (mindfulness intervention and health education) implemented for 17 minority children with an average age of nine and a half years old. The mindfulness intervention used the Mindful Schools program that focused on breath, movement, and generosity while the health education program focused on healthy eating and stress management. Each group of students participated in their corresponding program for 
10-15 minutes every day for two weeks (Liehr \& Diaz, 2010). Upon completion of the program, it was found that the children who took part in the Mindful Schools program reported fewer symptoms associated with depression and anxiety (Liehr \& Diaz, 2010).

In addition to a reduction in stress and anxiety, participating in mindfulness-based interventions allowed for individuals to accept different experiences in their lives, whether good or bad, and find clarity from these experiences (Alleva et al., 2014; Coffey et al., 2010; Erisman \& Roemer, 2012). The ability to accept experiences as is and not be judgmental towards them is important because it allows for an opportunity to understand that emotions come and go and that even during troubled times, it will pass. This is significant because as Alleva et al. (2014) found in their quantitative nonclinical study that being judgmental about experience often results in depressive symptoms and rumination. In this study, participants completed questionnaires that included The Kentucky Inventory of Mindfulness Skills, Ruminative Response Scale, and The Quick Inventory of Depressive Symptomatology (Alleva et al. 2014). These questionnaires allowed for researchers to determine the connection between rumination, mindfulness, and depression (Alleva et al., 2014). Rumination, which Alleva et al. (2014) describe as "reflective pondering" and brooding, often occurs when an individual is being critical of their experiences (p. 73). If this reflective pondering and judgmental attitude is addressed through practices such a mindfulness, it will be easier to regulate emotions and address depressive symptoms as they arise (Alleva et al., 2014).

\section{Challenges Associated with Mindfulness Practices}

There are some challenges associated with the integration of meditation and mindfulness practices in one's life. The literature is very limited surrounding the challenges that children and adolescents may face, therefore adult challenges in the clinical setting will be addressed. One 
could suggest that these challenges could affect children and youth in similar ways. Firstly, the use of mindfulness may pose a religious concern to some participants who are not fully aware of the practice (Sobczak \& West, 2013). This is a concern because some individuals may be apprehensive about participating in this program as they may feel that mindfulness practices does not align with their religious beliefs and traditions (Sobczak \& West, 2013).

It is critical that practitioners ensure that the participant is knowledgeable of the practice and that their questions and concerns are addressed appropriately (Sobczak \& West, 2013). Another issue surrounding mindfulness, especially in the clinical setting, is that it may not always be deemed appropriate depending on the needs of the participant (Shapiro \& Carlson, 2009). For example, Johanson's (2006) article noted that patients who have personality disorders or psychosis may have to seek other forms of counseling and therapy in order to have the skills required to be reflective of their lives and be mindful of their thoughts and feelings. Another challenge with engaging in mindfulness practices surrounds what is deemed an appropriate amount of time for practice. The traditional MBSR format consists of eight weekly sessions for two and a half hours per session (Kabat-Zinn, 2003). This format may be appropriate for some people, however, more or less time may be needed for mindfulness practices depending on individual participant needs (Baer, 2006). Another essential component of a MBSR program consists of 45 minutes of home practice for six days a week (Baer, 2006). This recommended amount of daily practice could pose a challenge, as participants may feel that it is a chore, as opposed to an extension of practices explored in the program (Baer, 2006).

Due to the nature of meditation, it is possible that hidden traumatic experiences may surface or resurface and many adverse effects of mindfulness practices often go unreported due to stating that the distress felt is a part of the reflective process of meditation (Farias \& Wikholm, 
2015). Farias and Wikholm (2015) described a 1992 study by David Shapiro who looked at the effects of meditation after attending a retreat. Through interviewing 27 participants with varying levels of meditation experience, he found that approximately $63 \%$ demonstrated one negative effect associated with meditation while $7 \%$ suffered negative effects such as pain, confusion, and panic (Farias \& Wikholm, 2015). Shapiro (1992) also found that participants who were more experienced with meditation displayed more adverse affects than the novice meditators in the group (Farias \& Wikholm, 2015).

Participating in meditation and mindfulness practices can bring up symptoms of anxiety, anger, nightmares, avoidance, delusions, hallucinations, depression, and psychosis (Farias \& Wikholm, 2015; Lustk et al., 2009; Sobczak \& West, 2013). In a qualitative study by Lomas et al. (2015), 30 adult males over the age of 18 , who were currently practicing meditation on their own, took part in two semi-structured interviews that were aimed at describing their experiences with meditation. The men noted that they found meditation challenging and that at times they felt physical discomfort, self-doubt, and a difficult time trying to concentrate and be mindful of the experience (Lomas et al., 2015). Participating in meditation often brought up thoughts, feelings, and sensations that were kept buried which resulted in increased anxiety and poor self-esteem (Lomas et al., 2015). These men also had a difficult time trying to incorporate mindfulness practices and a loving-kindness meditation in their daily lives (Lomas et al., 2015).

It is crucial that individuals guiding the practice should get to know their participants and be accepting of the fact that mindfulness may not be suitable at that moment in time. As Johanson (2006) described some issues that individuals with personality disorders face that may affect their ability to engage in practice. Getting to know the individual and collective needs of a group of participants can help determine an appropriate length of time needed for mindfulness 
practices and whether or not home practice should be modified. Engaging participants on a personal level could allow for practitioners to address adverse effects and modify the program accordingly.

\section{Mindfulness and Education}

Teacher Personal Practice. Crane et al. (2010) stressed the importance of teachers becoming familiar with mindfulness practices and incorporating them into their daily lives. As teachers are being mindful and engaging in practices such as deep breathing and yoga, they are acquiring the skills needed to teach children about mindfulness based on their own personal experiences (Crane et al., 2010). Crane et al. (2010) described the mindfulness teaching process that incorporated personal experience as being "in vivo" (p. 78). When an experience is 'in vivo' it involves teachers bringing in their personal reflections to their practice (Crane et al., 2010). As teachers continue to incorporate mindfulness into their own personal practice, they will act as a role model and will allow for an increase in their confidence and ability to initiate and facilitate mindfulness practices with their students (Crane et al., 2010).

Some research (Capel, 2012; Flook et al., 2013; Frank et al., 2015) has been done on implementing mindfulness-based programs for teachers and evaluating their responses towards the intervention. This is important because participating in a mindfulness-based program can allow teachers to become more familiar with the practice and find ways to incorporate different mindful exercises into the classroom. The personal effects teachers have experienced such as self-compassion directly extend into the classroom environment (Flook et al., 2013; Frank et al., 2015).

Flook et al. (2013) created a quantitative randomized controlled pilot trial and implemented a mindfulness-based stress reduction program adapted for ten elementary school 
teachers. The course was eight weeks long for two and a half hours per week (Flook et al., 2013).

Teachers were encouraged to practice mindfulness on their own for approximately 15-45 minutes a day, six days a week (Flook et al., 2013). In this program MBSR-trained instructors led practices associated with the breath as well as a loving-kindness meditation. Other practices made specific connections to the classroom and teaching practice. Since this program was implemented during the school year, teachers could use the strategies adapted for the education system in their own classrooms. Through this adapted intervention program, the researchers found that teachers felt they were more mindful and more self-compassionate. In addition, teachers felt as if they had fewer instances of burnout and that over the school year their stress levels were lower (Flook et al., 2013).

A quasi-experimental pretest-posttest comparison group study by Frank, Reibel, Broderick, Cantrell, and Metz (2015) lends support to Flook et al's (2013) findings that an implementation of a mindfulness-based program specifically targeted for teachers will result in lower stress levels and increased self-compassion. Thirty-six high-school teachers participated in an eight week adapted MBSR program for the needs of teachers. Each week, for two and a half hour sessions, participants took part in a body scan, eating and walking meditation, awareness of breathing, and mindful yoga (Frank et al., 2015). The researchers found that these teachers demonstrated an improvement in their ability to self-regulate as well as an increased ability to remain calm during stressful moments. These teachers felt as if their self-compassion levels were increased and that they perceived their ability to observe and not judge and react was improved (Frank et al., 2015).

Capel (2012) used personal narratives to explore the topic of mindfulness and mindlessness in the classroom. Mindlessness is described as "habit, functional fixedness, over 
learning, and automatic processing" (Langer, 1992 as cited in Capel, 2012, p. 668). Often teachers fall into using mindlessness practices due to trying to meet curriculum needs as opposed to looking at the needs of each individual child (Capel, 2012). By engaging in mindfulness practices, teachers have been found to be more sensitive and responsive to the individual and collective needs of students in the classroom (Capel, 2012). As teachers are more aware of student needs, it has been noted that they find more creative ways to allow children to demonstrate their prior knowledge and emerging understanding of new concepts. Ultimately the quality of learning for the students will improve if teachers display mindful traits that result in themselves being more involved in the moment-to-moment experiences of the classroom (Capel, 2012). By participating in mindfulness-based programs, teachers will become more familiar with these practices and ways to incorporate them into their lives. By making connections between personal experiences and mindful practices within the classroom, teachers will continue act as a role model for their students and help nurture positive student learning and improve well-being.

Shonin and Van Gordon's (2015) journal article adds to Capel's (2012) suggestions for teachers to practice mindfulness in their lives. Firstly, it is important for teachers who are interested in mindfulness to take the time to understand the core Buddhist teachings, in specific to those that relate to mindfulness and practice on a regular basis. By practicing on a regular basis teachers act as a positive example for their students. It was also stated that teachers should take time to center the mind and be in the present moment before teaching a class. Finally, becoming present with oneself, teachers have the opportunity to set an intention for the class and goals they would like the students to accomplish in their day (Shonin \& Van Gordon, 2015).

Student Learning. The effects of mindfulness practices implemented by teachers into the classroom can be seen in the executive functioning of pre-school, second, and third grade 
children. The executive function of a child includes processes involved in planning and carrying out goal-directed activity, working memory, and response inhibition (Flook et al., 2010). Flook et al's (2010) research examines how children who have poor executive functioning often have socio-emotional difficulties and suffer from lower academic functioning due to impulsivity and a lack in the ability to concentrate and understand material. Their quantitative randomized control study assessed the executive functions of 65 second and third grade children between the ages of seven to nine years old. These children took part in a 30-minute mindfulness session twice a week for eight weeks. Each session allowed children to develop an awareness of their senses, awareness of others, and an awareness of their environment. Children were assessed using tools that included the Metacognition Index, Behavioral Regulation Index, and the Global Executive Composite. The results of this study extended into the classroom and home environment where teachers and parents reported an improvement in the ability to regulate behaviours, thought processes, and an overall increase in executive functioning. Children who entered the program having a lower executive functioning responded better than those with average levels (Flook et al., 2010).

Similarly, Flook, Goldberg, Pinger, and Davidson (2015) used a randomized controlled design to look at how executive functioning could be affected through pre-school children's participation in a Kindness curriculum. Sixty-eight pre-school children were placed into either the Kindness Curriculum or waitlist control group (Flook et al., 2015). The Kindness Curriculum consisted of one 20-30 minute session for a total of 12 weeks. This age-appropriate Kindness Curriculum was designed for preschool children and used strategies such as reading books and integrating music and movement to teach children about emotion regulation, attention span, empathy, gratitude, and ways to share. Upon conclusion of the study, teachers reported that the 
children who took part in the Kindness Curriculum displayed gains in their social competence and improved levels of executive functioning whereas children who did not participate displayed more instances of selfish behaviour (Flook et al., 2015). Similar to the previous study by Flook et al. (2010), children who displayed lower levels of executive functioning upon entering the program displayed greater gains than students with average levels.

Black and Fernando's (2014) field intervention trial looked at the effects of a five-week mindfulness program on 409 elementary school-aged children in kindergarten to grade six. Teachers were asked to rate student behaviour before and after the intervention. Students were found to have an increased attention span, have improved self-control and calmness, improvement in participation of classroom activities, as well as heightened levels of caring and respectful behaviour towards others. Students who continued to receive additional mindfulness training had an increased attention span (Black \& Fernando, 2014). Similarly, Felver, Frank, and McEachern (2014) used a multiple-baseline single-subject study design to work with children using a mindfulness practice entitled, 'Soles of the Feet' created by Singh et al. $(2003 ; 2011)$. This intervention helps teach children different ways to identify conditions that may provoke aggressive behaviour and ways to avoid these triggers and focus on a point in the body in order to calm down (Felver et al., 2014). It was found that elementary children who typically displayed high levels of disruptive behaviour who went through this intervention were more academically engaged and displayed less instances of being off-task in the classroom (Felver et al., 2014; Semple, 2015).

The attention span of students can also be improved after mindfulness training. Napoli, Krech, and Holley's (2005) research presented results from a formative evaluation with information about student attention span from 11 teachers about 228 grade one, two, and three 
students. For 24 weeks, children participated in mindfulness practices that included awareness activities such as breathing, body scan and movement. Through these practices, it was noted that children focused better in the classroom, had less anxiety surrounding test-taking, and were better equipped to handle stress (Napoli et al., 2005). Children with ADHD behaviours displayed an improvement in the ability to be redirected to an appropriate task (Napoli et al., 2005).

Various studies have noted the feasibility of integrating a mindfulness program into an elementary school curriculum (Britton et al., 2014; Liehr \& Diaz, 2010; Viafora et al., 2015; Weijer-Bergsma et al., 2014). Britton et al. (2014) noted from randomized controlled pilot trial involving 114 students that mindfulness, through the use of mindful breathing, awareness of thoughts and feelings, and body sweeps, can be easily incorporated into the classroom resulting in increased relaxation, ability to concentrate, and lower levels of anxiety.

An experimental study by Weijer-Bergsma et al. (2014) divided 199 participants between the ages of eight to twelve years old into intervention and waitlist control groups (WeijerBergsma et al., 2014). A 'MindfulKids' curriculum was implemented twice a week for 30 minutes for a total of six weeks. This curriculum was adapted to be age-appropriate and focused on an awareness of sounds, bodily sensations, the breath, thoughts, and emotion regulation. Weijer-Bergsma et al. (2014) found that there was an increase in body and emotional awareness, less symptoms of anxiety, and fewer instances of aggressive behaviours. These low intensity mindfulness programs have been proven to be easy to integrate into various elementary and middle school classrooms (Wiejer-Bergsma et al., 2014; Viafora et al., 2015). As such, Viafora et al. (2015) conducted a quasi-experimental study and found that implementing mindfulness practices into middle school classrooms in both tradition and non-traditional settings to be feasible. The results of eight weeks of 45 minute weekly sessions with a mindfulness instructor 
included increased capabilities of managing stress and emotions as well as an enhanced sense of relaxation, increase in concentration and happiness (Viafora, et al., 2015).

\section{Summary}

The purpose of this literature review was to form a foundational background in mindfulness practice through learning about Buddhism and how modern leaders and practitioners Thich Nhat Hạnh, Sharon Salzberg, Jack Kornfield, and Jon Kabat-Zinn have described this practice. The literature suggests that the majority of research surrounding the effects of mindfulness practices has been conducted on adults in comparison to children and adolescents (Coffey, Harman, \& Fredrickson, 2010; Erisman \& Roemer, 2012; Flook et al., 2013; Frank et al., 2015; Gold et al., 2010; Leung et al., 2013; Van Aalderan et al., 2014; Van Dam et al., 2014;). The studies that incorporated the use of mindfulness practices in education were implemented in later primary grades, junior, middle school, and high school (Anand \& Sharma, 2014; Biegel et al., 2009; Britton et al., 2014; Mendelson et al., 2013; Viafora et al., 2015). However, some research was conducted with children who were in the targeted age range of between kindergarten to grade three, between three to nine years old (Black \& Fernando, 2014; Felver et al., 2014; Flook et al., 2010; Napoli et al., 2005; Semple et al., 2005; WeijerBergsma et al., 2014).

This study will contribute to the existing literature about the implementation of mindfulness practices with young children in the primary grades. The mindfulness programs implemented into the school system were conducted by researchers (Anand \& Sharma, 2014; Biegel et al., 2009; Britton et al., 2014; Mendelson et al., 2013; Viafora et al., 2015) as opposed to teachers initiating mindfulness practices with their students on their own accord. This research 
will provide a different perspective from teachers who are interacting with students for a period of time that is longer than the typical eight-week intervention period.

\section{Research Question}

What are primary teachers' perceptions of implementing mindfulness practices with young children in the classroom? 


\section{CHAPTER 3}

\section{Methodology}

\section{Research Design}

This study followed a qualitative descriptive research design using a thematic analysis approach. Sandelowski (2000) describes the purpose of a qualitative descriptive study as one in which a detailed summary of an event is written in everyday language which is easy to understand. A qualitative descriptive study is used when the researcher would like to describe an event in detail that is true to a particular experience.

This research used purposeful sampling in order to collect data from teachers that would be of great detail and provide enough information that would be suitable for addressing the research question (Sandelowski, 2000). The research question was addressed through the use of individual open-ended and semi-structured interviews and field notes in order to gain first hand knowledge of teachers' experiences surrounding mindfulness practices. These interviews and field notes made up the data set that was used for analysis. Sandelowski (2000) explains a qualitative content analysis approach as being a type of analysis that is interactive and allows for the opportunity to make adjustments upon further collection of new data. Using this type of analysis I was able to summarize the data, generate codes from the interviews, and represent the data true to the voice of each teacher who participated.

The data obtained for this study was analyzed through the use of themes and is reflective of the content. A thematic analysis approach was used to permit flexibilities and allowed for the descriptive data to be represented in a way that is connected to the research question (Braun \& Clarke, 2006). Ultimately the descriptive nature of these summaries, placed into themes, allowed for the opportunity to provide insight into teachers' perceptions of implementing mindfulness 
practices with young children in the classroom (Sandelowski, 2000).

\section{Ethical Considerations}

Prior to data collection, an application to the Ryerson Ethics Board was submitted which outlined the research methodology and procedure that I proposed to undertake. Relevant documentation such as recruitment letters and interview guides were attached to the document. Approval from the Ryerson Ethics Board demonstrated that this research followed all necessary guidelines in terms of methodology, recruitment, confidentiality, and risks. A potential risk of this study included feelings of discomfort, which was mitigated by providing participants the opportunity to skip questions or withdraw from the study if needed without any penalty.

Throughout the research process, I employed various ethical considerations. Before agreeing to participate in this study, interested participants were given a copy of the consent form to look over in order to decide if they wanted to be involved in this study. Participants were not pressured into signing the consent form and were given the opportunity to ask as many questions needed. Before data was collected, I ensured that participants had informed consent as they were told about the research project, confidentiality, anonymity, dissemination of findings as well as the right to withdraw from certain questions or the study altogether (King \& Horrocks, 2010). Each participant was told that they would receive a copy of their transcript to look over as well as future findings and the completed research paper. Employing these types of ethical considerations allows participants to feel respected and have authority over their own participation and right to withdraw.

\section{Recruitment}

Participants were recruited through purposeful sampling. This approach was chosen based on similar traits or characteristics participants had (Creswell, 2008). I purposely sampled 
individuals based on their membership in a holistic educators list serve and mindfulness newsletter list serve in Southern Ontario (Creswell, 2008). The initial sample size was kept to four to six participants in order to be able to study the individuals and collect a large amount of information surrounding the topic (Creswell, 2008). In order to ensure confidentiality of the names and emails on the list-serve, my supervisor sent out a recruitment letter on my behalf to a gatekeeper of the two recruitment sites (Appendix A). Interested participants were asked to contact me to learn more about this study. It was determined that the first five individuals who responded to this recruitment letter and who met the inclusion criteria were selected. The inclusion criteria required that the participant must be an educator, who regularly, and who has regularly in the past, practiced mindfulness with children between the ages of four to eight years old in kindergarten to grade three classrooms.

There were some challenges surrounding recruitment of participants. Labour unrest in the school boards in Ontario and potential strike action was occurring. Many of the educators on these list serves were part of school boards who were affected by these events. The possibility of a strike and the timing of recruitment at the end of the school year may have affected the response rate to the email. When five individuals responded to the recruitment call, one responded too late and due to being out of town was unable to take part.

\section{Participants}

Four teachers participated in my study. Each participant was Caucasian. All met the criteria of teachers who have previously, or were currently using mindfulness practices with their students in kindergarten to grade three classrooms. In order to ensure privacy, each participant was given a pseudonym. 
Participant one: Melissa* (pseudonym). Melissa is a certified teacher, yoga teacher, singer-songwriter, storyteller, painter, performer, and freelance artist. Her educational background is radio and television before she obtained her teaching degree. She has experience working as an educational assistant and has been certified as a teacher for ten years. She is currently employed as a kindergarten to grade five music teacher in a school board located in an diverse urban area in Southern Ontario where she has taught for five years. Melissa started yoga in 2004, practicing meditation in 2008, and has been practicing mindfulness for seven years. Through her work as a teacher and freelance artist, she combines her love for teaching and producing as well as the arts. In her freelance work, she is a teaching artist who does interactive performances and workshops with children and adults.

Participant two: Megan* (pseudonym). Megan is a registered early childhood educator, certified teacher, and an instructor in an urban area in Southern Ontario. She taught kindergarten between 2006-2010 before enrolling in graduate studies. Megan started practicing yoga and mindfulness in 2007 as a way to avoid burning out from the stress of teaching. She found that she had a better connection with the meditative components of yoga as opposed to the physical. In 2012, for her doctoral dissertation, she conducted research using mindfulness practices with kindergarten students and compared the results between the intervention and control group. She is currently an instructor in a university and community college in Southern Ontario. She has plans to conduct research on the effects of teaching a mindfulness course with students enrolled in the Early Childhood Education program at the college she works at.

Participant three: Leslie* (pseudonym). Leslie is a certified teacher who has been teaching for ten years. She is currently completing her Master of Education degree at an Ontario university. She has experience teaching children in senior kindergarten and with children ages 
eight to eleven in England. She has also taught children between the ages of two to four in an independent school in Ontario. Upon being hired in a school board in an urban area in Southern Ontario, she taught music for students from grade one to five before her current position as a kindergarten teacher. Next year she will be teaching grade one students. Leslie has taken a course in meditative practices as well as a mindfulness workshop during her graduate degree. She has been practicing mindfulness for a couple of years and has been recently implementing these practices into her classroom.

Participant four: Michael* (pseudonym). Michael is a certified teacher who has been teaching for seven years. He has just recently completed a Master of Education at an Ontario university. He has experience working with children in a summer camp and has taught students from kindergarten to grade two. Presently he is teaching grade one at a diverse independent school in an urban area in Southern Ontario. He started doing martial arts when he was twelve years old where he started incorporating meditation into his life. He has been practicing meditation for 14 years and regularly practices with other individuals at a multi-faith centre in Southern Ontario. Michael has been incorporating mindfulness practices into his classroom for the past two years but has felt that his approach to teaching has been similar to what mindfulness teaches students.

\section{Data Collection}

The use of semi-structured and open-ended one-on-one interviews and field notes for data collection was chosen because it allowed for participants to be able to describe their experiences of the topic being studied (Creswell, 2008). The interviews followed an open-ended and semistructured guide. Open-ended questions were used to elicit responses from the participant that weren't constrained or guided (Creswell, 2008). Semi-structured questions were also used to 
ensure that the interview did not go off-topic.

The interviews were conducted over a four-week period in a location outside of the participant's place of employment. Participants chose a place of convenience for the interview. If the participant did not state a preference of where to be interviewed, a meeting room at Ryerson University was used. There was one interview session per participant, which was between fortyfive minutes to an hour. Before the interview commenced, I ensured to build rapport with the participant through general conversation. The interview questions I used included a variety of background, experience, opinion, feeling, knowledge, and sensory questions (King \& Horrocks, 2010). The background question was addressed by asking the participant about his/her experiences working with children. Participants were asked to describe their own experiences with mindfulness as well as their thoughts of the role mindfulness places in the lives of young children. As well, questions that surrounded the types of mindfulness practices used in the classroom and effectiveness were discussed. Probes were used to elicit more information from participants (Creswell, 2008). Interviews were recorded on an iPad application and were later transcribed by the researcher using a transcription program. During the interview, field notes were taken in a journal to ensure that information was recorded if the recording was inaudible. The use of note taking also allowed me to follow up on statements made throughout the interview session (King \& Horrocks, 2010). Each audio file and journal notes were immediately given a pseudonym in order to ensure confidentiality. During transcription, any identifying names of individuals or places of employment were not included. After each audio file was transcribed, member checking was used to allow participants the opportunity to verify if the data on their corresponding transcription was correct (Creswell, 2014). 


\section{Confidentiality and Anonymity}

It is imperative that as a researcher, I protect my participants, develop trust, and ensure that there is no possibility of misconduct with personal information (Creswell, 2014). As such, confidentiality and anonymity was maintained throughout the research process. All consent forms as well as my research notes, audio files, and transcriptions were put onto a secure USB drive and kept in a locked cabinet in my supervisor's office at Ryerson University.

\section{Authenticity and Rigour}

In qualitative research, it is important that authenticity is maintained and that participant experiences are accurately represented (Seale \& Silverman, 1997). Interviews were audiorecorded as they provided a detailed account of the interactions and were accurate representations of the participants' experiences (Seale \& Silverman, 1997). In case of a malfunction with the audio-recording device, I took notes in a research journal to ensure that information was not lost. Qualitative validity and authenticity was ensured through the use of member checking (Creswell, 2014). Each participant was emailed a copy of their interview transcript and findings and was given an opportunity to check for any mistakes or areas in which they wanted to change. They were each given up to two weeks to make any necessary changes and either add or omit information. The findings were written in a rich, descriptive way to allow for a realistic representation of the data collected (Creswell, 2014). Reporting the findings through a descriptive approach allowed for participants' words to be accurately represented and allow for the reader to discover these experiences (Seale \& Silverman, 1997).

\section{Data Analysis}

For this research, the data collected was analyzed through a qualitative descriptive thematic analysis. The data set consisted of four interviews and their corresponding transcripts 
and field notes. Participants' experiences were analyzed and organized into themes using a thematic analysis. These experiences were described in detail at a surface level rather than interpreting the event in order to allow the data to remain authentic.

A thematic analysis was chosen as it is flexible and allows for identification, analysis, and reporting of themes within a data set (Braun \& Clarke, 2006). Braun and Clarke (2006) discusses that these themes must be described in detail and representative of the data. Using an inductive approach as a form of analysis, data was coded without pre-existing frameworks or codes. The themes that emerged from the codes were semantic as they were a direct result of an analysis of the data without searching for meaning beyond what was collected from the interviews and field notes. Using this type of analysis allowed for a rich, detailed description of the themes and further provided the reader with an opportunity to gain insight into the experiences and perspectives of the participants.

To initiate the thematic analysis process, I transcribed each audio-recording file verbatim while maintaining the same style in order to ensure consistency (King \& Horrocks, 2010). The transcription process allowed me to initially become familiar with the data and initiate analysis procedures. After reading each transcript, a preliminary exploratory analysis was used to allow for a general sense of the emerging concepts and ways to organize themes and ideas (Creswell, 2008). After becoming familiarized with the data, I manually created initial descriptive codes about what was of interest within the data and started to group codes together. Codes that were similar in nature were combined to create overarching themes. A theme is described by King and Horrocks (2010) as a "recurrent and distinctive feature(s) of participant' accounts, characterizing particular perceptions and/or experiences, which the researcher sees as relevant to the research question" (p. 150). The four themes that emerged were related to the research question 
surrounding teachers' perceptions of implementing mindfulness practices and were supported with relevant data and quotes from each participant.

\section{Voice of the Researcher}

It is important that I address the position that I bring to this study as it has an influence on my research (Olson, 2011). My educational background consists of an undergraduate degree in Early Childhood Studies as well as a Bachelor of Education for the Primary/Junior grades. I am a Registered Early Childhood Educator and Ontario Certified Teacher. Throughout my various practicum opportunities, I have had the chance to work with teachers, children, and families in child care centres, private, and public classrooms. During these practicum experiences, I became aware firsthand of the challenges that many children face in the classroom. I have observed children who demonstrate anxiety and social-emotional problems that have appeared to hinder their ability to learn to their fullest potential. Having seen the struggles that children appear to face in the classroom has prompted me to learn about ways in which as a teacher, I could help address such concerns.

Volunteering in a classroom and implementing mindfulness practices prompted me to want to further explore how these practices could be implemented into my own life. I am still very new to this practice and am interested in learning about how mindfulness can be further integrated into the daily routine within the classroom setting. In my personal life, I have been trying to find different ways to incorporate mindful practices into my day and be more reflective of my actions. I am trying to be more focused on a task at hand and take the time to observe my breath and emerging thoughts. I am looking forward to this mindful journey I have chosen to embark on and am looking forward to creating a holistic classroom in the future. 


\section{Summary}

This qualitative descriptive research design addressed the research question I created surrounding primary teachers' perceptions of implementing mindfulness practices with young children in the classroom. The use of formal one-on-one interviews allowed me to be able to have a personal conversation with participants about their experiences and familiarity of using mindfulness in their own lives and with the students they have taught. Each participant was made aware of how the data collected would be used and how confidentiality and anonymity would be maintained. Using a qualitative descriptive thematic approach to analyze the data allowed for an analysis that would be representative of the data set and allow for the creation of relevant themes. The following chapter will include the findings that emerged from the interviews 


\section{CHAPTER 4}

\section{Findings}

This study investigated primary teachers perceptions of implementing mindfulness practices with young children in learning environments. Four open-ended and semi-structured interviews were conducted with primary grade teachers in Southern Ontario. Conducting one-onone interviews allowed teachers the opportunity to describe their experiences with mindfulness practices in their own lives and how they integrate this practice when working with young children. Using a thematic analytic approach, four themes emerged from the interviews that were representative of the data collected. The first theme looked at the motivating factors for the inclusion of mindfulness practices in the classroom. The second and third themes described the various practices used within the classroom and the perceived benefits observed from students after implementing different practices. However, even though these teachers have used mindfulness practices with their students, there were challenges that occurred that could hinder successful implementation. The fourth theme described the challenges participants faced initiating and applying mindfulness practices into their classrooms.

\section{Motivating Factors for the Integration of Mindfulness Practices in the Classroom}

Melissa began learning about and practicing mindfulness as a result of trying to address some of the challenges she has had in her life. Working in an inner city school, she found herself stressed out and wanted to find ways to alleviate her stress. Some of the teachers at her school were interest in Buddhism, meditation, and yoga, which prompted her to research about the topic and find ways to help with some personal difficulties she was going through and bring loving kindness into her life. As she integrated mindfulness into her life, she felt that it was very 
experiential and stated that one must experience it in order to facilitate it with young children. She described this experience as, "It is a different thing to have experienced something personally versus learning about it... Mindfulness is an experience, it is an experiential tool, and it is very rooted in personal experience. That's what it's all about."

Teacher-related stress was a motivator for the inclusion of mindfulness practices in Megan's classroom. In her first year of teaching, she taught kindergarten with 27 students in the morning and 27 students in the afternoon. She found that with the large class size and challenging behaviours that it was difficult to teach these children.

Megan: I was teaching in a fairly rough area and they came to school with very little tools on how to self-regulate or how to even talk about their emotions. They were aggressive, and [had] lots of tantrums. [There were] some pretty intense behaviours.

The difficulties she faced in the classroom prompted her to find a way to avoid burn out. As she was starting to practice mindfulness in her own life, she found that she was more self-regulated and that being more mindful of her reactions in the classroom helped to change the classroom dynamics in a more positive way. Classroom dynamics were changed due to incorporating practices she learnt from yoga and meditation.

Megan further described the importance of teacher practice in the classroom, especially for early childhood education students.

Megan: A lot of students are coming with their own wellness issues of anxiety and depression and making accommodations for all of those things... and the idea [is] that if you can't take care of [yourself], you are not going to be able to take care of young children and you are not going to be fostering the healthy development of young children 
- so kind of teaching those students to attend to their own wellness just to be better educators.

Michael further described the importance of including mindfulness practices into his daily classroom routine as a way for children to escape. He felt that the stress and need for children to relax is very important.

Michael: Children don't really have that metacognition to say, like an adult would, that I am just really tired and I want to relax. They are kind of just like go, go, go, until they crash, so having meditation is like an activity, something to do, without crashing, they can do it and feel calm.

Leslie was first introduced to mindfulness practices when taking courses in her Master's degree. In these courses her professor spoke about mindfulness practices and how it is a valuable tool to incorporate into daily practice and in the classroom environment. This sparked her interest in ways in which she could adapt practices and implement them into her classroom when working with young children. Due to the challenging group of students with varying needs and instances of anxiety, she felt that it was necessary to try these practices with her students.

Each participant had various motivating factors as to why they started practicing mindfulness meditation and reasons for extending their personal practice into the classroom. Melissa and Megan had similar motivating factors, as they were both interested in using mindfulness as a way to cope with personal hardships and teacher-related stress. Michael and Leslie started to integrate mindfulness practices into their classroom based on an interest from graduate courses and an interest in finding a tool for children to reduce stress. The motivating factors based on personal concerns and an interest in addressing childhood well-being has prompted participants to integrate different mindfulness practices into their classroom 
environment.

\section{Practices Used in the Classroom}

Each teacher spoke about the different ways in which they incorporated mindfulness into their classroom. When Melissa first introduced practices associated with mindfulness, she implemented a yoga routine for children with physical disabilities:

Melissa: One day I ended up by accident getting into yoga one day with the kids, because we were doing physiotherapy with them. They were out of their wheelchairs ... and we were just hanging around, and the teaching assistant said, "Oh, let's not bother getting into our equipment today." Because they had equipment for weight bearing and stuff. We were just relaxing on some mats, and then I randomly just started spelling letters with our bodies like 'A, B, C, D' and then I just started throwing in some yoga activities. I hadn't used my yoga certification much up to that point aside from teaching a few classes for friends... and the kids loved it! ... and they threw their arms around me!

Melissa is a prep teacher in an elementary school where she had used yoga and a variety of different breathing exercises with her students. With her kindergarten students she integrates these breathing exercises at the beginning of every class:

Melissa: So I do breathing exercises, like animal breathing, we Om together [at the] beginning of every single kindergarten class. We also do an exercise called 'Blow the balloon' where we pretend we are blowing up a balloon... So its built into the beginning of every, because I'm the prep teacher they see me twice a week for 40 minutes. So I build that into the beginning of every class, so it's like, they don't even realize that they're building those habits for them[selves] in a fun and engaging way.

She also used a breathing exercise, which was entitled, 'Take 5' which requires students 
to breathe in for five seconds, hold the breath for five seconds, and breathe out for five seconds. Melissa integrated music into her mindfulness practices and an awareness of sound through the use of a Tibetan singing bowl and by singing songs with positive messages. She described the use of the singing bowl as 'I'll have them put their hand up and then I'll tap it, and they'll bring their hand down until the sound disappears." She often plays a First Nations buffalo drum and chants "Om" when engaging in mindfulness practices with her students.

When implementing mindfulness practices in her classroom, Megan would typically start the class with mindful breathing followed by a Tibetan singing bowl awareness activity.

Megan: I have a Tibetan singing bowl that I use and I have them listen. It's actually the first lesson of the program because it is a little bit more concrete for kids to use. You start telling them that we have a singing bowl and to make sure you listen to the sound until they cannot hear it anymore and then to put their hand up when they don't hear it anymore. The first time we do it they all put their hand up, and we're like, no you gotta wait.

In her classroom, Megan would also use mindfulness practices such as mindful listening, mindful movement, mindful walking, and mindful seeing. In each of these practices, she would ask students to "put their mindful bodies on."

Megan: I get them to put their mindful bodies on. That's sitting with your back straight, and still body, and I just have them look around the room and notice things that they hadn't noticed before... But with kids, what I tried to do is really get them to practice that on their own when they are at home. At home or at school, [I would] say: when you're out on the playground today, I want you to practice mindful seeing and see if you can notice anything that you haven't noticed before or hear sounds that you haven't heard 
before.

In addition to being mindful of their surroundings, the children in her class also had the opportunity to use a mind jar which is a jar filled with a material, such as glitter or beads, that requires the child to shake and let settle. Lastly, Megan often uses a loving-kindness meditation, which she says students really respond well to. In this meditation, she would encourage her students to send loving thoughts that extend outwards into the universe.

Similar to Melissa and Megan, the third participant, Michael used breathing and meditation as the main focus of mindfulness practice in the classroom. He used different strategies such as smelling a flower or blowing out a candle to facilitate breathing. He stated that these techniques are child-friendly and are easy to remember for young children. Other ways in which mindfulness is facilitated in the classroom is through the use of a thank you, kindness, and thought circle.

Michael: We do a practice when we do circle [time], we will do a thank you circle where they will all go around and have turns to say thank you to someone whether they are in the classroom or not. Or we do a kindness circle, where they say something they did that was kind or something that someone else did that was kind. We also have a thought circle where they go around and one at a time, just say one word or phrase about what they're thinking about. So it might be that they might be thinking about a play date or thinking about chocolate cake or thinking about getting picked up at the end of the day. Throughout all of these circles we have a big quartz crystal that's big enough for them to hold and they pass it around. That's their speaking stone. So in a way, of being mindful, they are not allowed to speak unless they are holding the speaking stone.

In addition to the mindful breathing and circle activities, his students have had the opportunity to 
learn about how to behave more mindfully and become aware of the other students in the classroom. This awareness has also extended to a focused portraiture where students have the opportunity to create a portrait of themselves at the beginning and end of the year.

Similar to the other participants, the fourth participant, Leslie, used different various mindfulness practices in her kindergarten classroom that focus on deep breathing. Concrete associations such as smelling a flower or blowing out a candle were also used to encourage the deep breathing process.

Leslie: In a small group we'll do where we focus on the breath and I teach them how to do deep breaths as well because they don't know how to do that. So you just tell them to take a deep breath and they're like, "What does that mean?" So we smell the flower and blow out the candle. That's a good one. Someone taught me that years ago - a speech language pathologist taught that to me. It's good because you teach them [the movements] and they practice that a few times and eventually they can let go of the actual movements of the hand and they can just take the breaths.

The activities she implemented into her classroom surround the five senses. She encouraged an awareness of sounds by playing music and asking the children to close their eyes and listen to the music and think about how it makes them feel. She often has a discussion with her students afterwards, which allows them to describe their feelings and what they have heard. An acknowledgement of the sense of touch occurs when she creates an enclosed box, which she calls a "feely box", with an object inside. Her students are asked to feel what is inside of the box and try to determine what it is. In addition to this feely box, Leslie facilitates the awareness of emotions through the use of "fuzzy buddies."

Leslie: We call them our fuzzy buddies, and they're just these little cards of these fuzzy 
buddies and one looks really angry, and one's really happy, and they kind of go in a spectrum. I put them all up and colour them in different colours. Each day they go up and choose how they're feeling that day and they put it under whatever one it is. Most of the kids will be in the semi-happy, some might be really excited, so they'll be under the excited ones. One might be excited, and I'll say, “what's going on?”, and they'll say, “oh I lost a tooth or something."

Leslie set up a calming corner in her classroom for students who feel that they need to calm down. This calming corner had different strategies put up which include pictures of things to do to calm down such as counting to ten or taking a deep breath. She had also integrated another practice during circle time. She will say different words such as friendship or peace, and will ask the children to think about the words and what it means to them. Leslie also uses a strategy to help address the restlessness of the young children in her classroom.

Leslie: We'll sit in our chairs and wiggle in our chairs for a whole minute and be really mindful of wiggling our whole bodies. Which makes them wiggle. So I've done that with the kids and they love it, and they can bring it back. They can get their wiggles out and we can bring it back.

Using strategies such as wiggling allows for children to help let out distractions and focus. By integrating different approaches such as these into the classroom settings allowed for teachers the opportunity to observe whether or not mindfulness practice resulted in any perceived benefits.

\section{Benefits of Mindfulness Practices with Children}

Each participant described the benefits that they have observed by integrating mindfulness practices into the classroom setting. Melissa described one of the main benefits of 
embedding mindfulness practices into the lives of young children is that there is a reconnection to themselves and others:

Melissa: Mindfulness is the reconnection that starts within yourself. It's like making peace within yourself, and that peace reverberates and extends outwards to your community, to your family, your friends, and I would say the society.

She discussed children making connections to the body and mind through the use of these practices.

Melissa: Mindfulness is connecting them with their body, with their mind, and giving them a tool later on that can help them calm down the things that they're dealing with that may be bigger than kindergarten problems.

In her classroom, she noticed that the children responded well to practices such as singing positive songs, chanting "Om", and breathing. The children were very responsive to the songs and "when they came in they really wanted to sing those songs right away." The use of the "Take 5' breathing practice has also been a useful tool for children to take a moment to stop, take a breath, and calm down.

Melissa: I can't remember if it was a grade one or grade two student, on they're own when they were feeling stressed out, I saw them do the breathe in for five, hold in for five, let it out for five, which was so awesome to see. And I hadn't even done it that much with them

When her students participated in these breathing exercises, Melissa noticed an overall sense of calmness in the classroom. In regards to the classroom energy, "if it went from [a] ten high, it might go down to five [after practice]." The lowering of energy to a calm ' 5 ', is a great 
achievement as she stated that, "they may not calm down to a zero because these kids may never get down to a zero."

Megan has also perceived there to be many benefits from using mindfulness practices in her classrooms. She stated that practicing mindfulness was a great tool for addressing the socialemotional aspects of the child and allowed them to learn about their emotions and how to deal with them.

Megan: The social emotional component of mindfulness is also really appropriate for that age group when they're learning about emotions and how to deal with strong emotions and then the academic side of it is that if you are more self-regulated than it's easier for you to learn.

Through the implementation of a mindfulness program in the classroom, she noticed that the overall classroom dynamics improved greatly. For example, she observed improved relationships amongst the children and that there was less stress and less instances of conflict. Megan felt that using a practice such as the loving-kindness meditation on a regular basis had positive effects on the relationships between her students. One notable experience happened with two young girls who often did not get along:

Megan: I had done a kind of a loving-kindness meditation and I had purposely and strategically paired them up with a kid, but not all of them, but some of the kids that I knew were having a hard time with each other and I would pair them up. I would go through this loving-kindness meditation where they had to recognize that they aren't friends with someone who is just like them, who feels sadness, just like they do and I went through this whole adult-type and adapted for them and at the end they all hugged each other. It was beautiful and then later on that day, two of the girls that I had put 
together on purpose because they were fighting all the time, and they were just playing so nicely together and they were telling me how they love each other now, and it was just that kind of thing. I was like, “They get it.” They were like, “Oh right, this is just another person like me." I really thought that was powerful so those meditations are good for that age. It's a little more concrete for them because they are learning about emotions in so many different ways that this just kind of ties it together for them.

Megan felt her students were really starting to understand what it meant to be mindful and to notice things about their environment and classmates that they had never noticed before. As well, the children were very responsive to the different practices and when given the choice to sing a song, read a book, or meditate, they would choose to meditate. She also stated that parents noticed the effects of the practice at home where one of her students said that during a tense moment, he asked his family to sit down and put their mindful bodies on.

Observations of the effects of mindfulness practices were also discussed in doctoral research she conducted in 2012. Megan implemented a six-week mindfulness program with kindergarten students that occurred three times a week for twenty minutes a session. She used a mindfulness group and a randomized control group. It was found that the children who were a part of the mindfulness group were more self-regulated, more pro-social, and appeared to be less hyperactive.

Leslie also noticed some of the positive effects of implementing different mindfulness awareness activities with her kindergarten students. She noticed that children were being more mindful of their emotions and they were developing a sense of empathy within themselves. 
Leslie: I find it helps develop empathy within them as well, just being mindful of those emotions because they don't always know how to describe what they're feeling and how they're feeling.

She has also noticed a difference in her students' awareness of the different senses. For example, using the sense of sound, her students would acknowledge the sounds and were able to describe how the sounds made them feel. When using the sense of smell, the children were found to be able to better describe what they smelled. Leslie had also noticed that the use of mindfulness practices with her students was beneficial for all students with some benefiting more than others. One of her students often had difficulty paying attention in class and redirecting his behaviour for more productive learning.

Leslie: So he came into our class and we only had him since about mid October and at first it was like a tornado, you know, and I'm not saying he doesn't still have those moments but I'm finding the more time I spend with him say, hey look, let's plan, let's think.

She noticed that there has been a subtle difference with the young boy and that he was calming down.

Leslie: My early childhood educator does the same thing, she'll say let's slow down, you're not in trouble, we just need to calm down a little bit. Let's take a few breaths, where are we going, you know, this isn't working well, playing over here with so and so is just no... You're knocking things down, you're running, you're jumping on top of him, let's find something else, let's redirect. So having those moments where we kind of let him be kind of mindful of where he's at and how he's responding to the other kids. He 
responds well, he's a very smart boy. So I'm finding the short-term effects with him are positive. Subtle, but positive.

Another young girl in her class demonstrated that she was really becoming aware of her classmates and ensuring that she included them during play time.

Leslie: It was at the water table and they were playing around the sensory table and a lot of them wanted in because we just put a bunch of bubbles and cool things. So there's, you know, ten of them trying to get in there and she was standing there and said, "I'm just trying to be mindful of my friends," and the fact that they want to play with it too.

She described how a previous student of hers who had high levels of anxiety was observed to be doing better in grade one after being in her classroom the previous year.

Leslie: Then you know, the little boy I had with the anxiety, those long term effects I'm seeing that because he's doing a lot better with that now. You know, he's happier, he's calmer, he's doing well in grade one, and he's excited in grade two. Where it used to be changes from, I don't know how much he's doing this year in his class but I do know that his teacher, um, does different activities and stuff with him and I did pass on, you know, the things I found that worked with him. So I don't know that he's doing those things necessarily but I wouldn't be surprised that maybe he's giving him that time to draw and talk about his pictures and all of those pieces too so that can continue. It's really valuable. Lastly, Michael described his perceptions of the benefits of the mindfulness practices he implemented in his classroom. He noticed that children were more detail oriented when completing coursework and that they were becoming more aware of their behaviour. Through participating in the various activities he used during the day, he noticed that children were using 
vocabulary around being more mindful of their bodies and of their peers. He also noticed the difference between his class and other classrooms at his school:

Michael: I can see it in comparison to other classes with teachers who don't practice mindfulness and sometimes those classes aren't as well adjusted in some ways - they're just wild or the teacher just can't seem to manage their behaviour.

The perception of the positive effects of mindfulness extended into the home life as he stated that one of the student's parents saw their child sitting on their bed using meditation as a calming mechanism.

Participants found that by integrating mindfulness practices into their daily routine resulted in noticeable changes in student behaviour and overall classroom dynamics. There was a sense of calmness to the room and they felt that the children were more accepting, aware of their classmates, and more empathetic. Children were more aware of the senses, mindful of emotions, and the social-emotional domain was addressed. Children paid more attention during the day and were more detail oriented in their play and work. However, even with the various benefits noted by the participants, there were often some issues initiating and implementing mindfulness practices into the classroom environment.

\section{Challenges for the Implementation of Mindfulness Practices}

Melissa described the issues she faces with implementing a holistic practice such as mindfulness into her classroom. She felt as if the school board is not configured to facilitate the arts or different types of holistic practices. As well, with an increase in cutbacks and the number of students in her classroom, which can range up to thirty children, she found it difficult managing safety and behaviour aside from trying to implement this practice. She describes some of the challenges that she has working in a demanding job such as teaching. 
Melissa: There are lots of teachers at my school, including me, who yell because sometimes literally, like for safety reasons to get them down the hall, or to stop doing something harmful, you have to yell and raise your voice. It feels terrible inside of your body when you yell at kids. I hate it. And then you're so exhausted because it's such a demanding job, sometimes you're just so tired that you yell. It's like, you know, parents having a bad day. You know what I mean? When you're parenting thirty kids at a time that are so complex. So [it is important] to be able to find a peaceful way to calm them down that feels better for me, and ultimately feels better for them. And it might take a bit longer, but that's okay.

When asked about if she noticed any issues surrounding mindfulness in the classroom, she responded: "The only negative thing would be... how it doesn't fit with the current system". She further explained another challenge she had trying to incorporate mindfulness in her role as a prep teacher.

Melissa: I really feel within the board, I need more support, more time to develop this new curriculum, because we're just expecting to develop it on [our own]. I mean, I've spent thousands of dollars on my own training and this is what teachers do, right? Which I feel is wrong. I need money, I need support to develop it, I need a different kind of schedule as a prep teacher 40 minutes is sometimes too short, sometimes too long. It needs to be a more fluid structure in our time schedule. There needs to be more teamwork, there needs to be more time for reflection and talk and collaboration and more positive attitudes from the leadership. Because the leadership if they don't understand it, or if they understand, it is like if they don't know how to do it, they might not be able to create a safe environment for you to take risks, try something so new, and pioneer, and if 
you're totally not being supported to do that, it'll be a draining experience. And that's been my experience.

Melissa found it very difficult to try and implement something new in the classroom with the hierarchies of decision makers above her. She felt in terms of implementing this practice that she had a lot of responsibility over her students but little decision-making powers.

Like Melissa, Megan felt the stress associated with trying to implement a mindfulness routine with her increasing class size. In her first year teaching, she had approximately 31 students in her classroom. The large class size made it difficult for her to teach lessons or integrate mindfulness practices.

Megan: I tell stories about it like I would have, like a fly in the room, and it was like my whole lesson is out the window because there's a fly in the room and all the kids are freaking out. There are 31 of them and it's like, there goes that lesson. (laughing) It's like you have no control, I mean it's like that with any size, but when there's more kids it's more of a problem.

Leslie experienced similar challenges when implementing mindfulness practices in her kindergarten classroom. With a large class of 28 children, she found it very difficult to have sessions in a large group, which prompted her to work with small groups of children at a time. Through her experiences she noticed that when working with a large group there were too many distractions, which made it very difficult to obtain the attention of all students. Even when working with a small group of children, at times she found it hard to set aside time for mindfulness as the children might be inattentive that day. Some children in her class had anxiety as well as high needs and required attention for the majority of the day. Even with the different 
needs of all of her students, she still tried to use different practices with them and acknowledges the fact that they are still very young children.

Leslie: [You have to] be mindful of the fact that this is just their innate natural drive for some of them to make noise and throw things and roll around, and that's just how they roll, quite literally.

Various parameters have to be set in order for the children to engage in the mindfulness practices. She stated that a struggle with implementing mindfulness was around the timing of day, distractions in the nearby classrooms, and her own ability to be mindful. She expressed, "I find as long as I set it up so that it is as conducive as possible, then usually I notice they get something out of it. There's always the kid who's not going to be into it." At times, she noted that if her mind was at a different place or that she was feeling stressed out that the children did not respond as well, "I have to be present with them too for it to work. If I'm not present with them, then they're not going to be present with me."

Michael did not note any issues trying to implement a mindfulness program into his classroom but described his wishes for collaborative practice.

Michael: I really wish that more teachers practiced it because then we could scaffold it. So starting with that in grade one, and then in grade two they actually build up to thinking about and just seeing how it would progress throughout the years... It would be interesting to see how kindergarteners approach it and how in grade three they approach it.

Three out of four participants described some of the challenges they have had trying to implement mindfulness practices into their classroom. It was found that increasingly large class sizes, scheduling, and lack of decision-making powers, made it difficult to facilitate holistic 
practices such as mindfulness. The current education system is not set up in such a way that provides the teacher the opportunity to take risks and receive the funding required to develop and introduce new practices. Michael encourages more teachers to practice mindfulness, especially from a young age, and implement it into their classroom because it will allow for an opportunity to scaffold throughout the years and build upon ideas. The following chapter will make connections between participant experiences and the literature by comparing the findings surrounding practices used, perceived benefits, and feasibility of implementation. 


\section{CHAPTER 5}

\section{Discussion}

\section{Overview}

The purpose of this study was to uncover primary teachers' perceptions of implementing mindfulness practices with young children in their classrooms. The findings provided insights into the types of practices being used in the classroom and their perceived benefits. Other themes that emerged included motivators for including mindfulness practices and challenges surrounding successful implementation of practices in kindergarten to grade three classrooms. The participants stated common practices that they have used which included mindful breathing, mindful movement, awareness of the senses, loving kindness meditation, and different practices implemented during circle time that focused on positive thoughts. Participants observed that by implementing mindfulness practices in the classroom children became calmer, more open to expressing their emotions, and develop more friendships. It was observed that students were more aware of their actions and there were fewer instances of anxiety-related behaviours. The teachers expressed their motivation for including mindfulness in their teaching practice as a result of trying to avoid burnout in the classroom and address childhood issues such as anxiety. However, due to large class sizes and lack of resources and funds, often participants found it difficult to more fully implement mindfulness practices with their students.

\section{Practices Used in the Classroom}

Some of the practices used by the participants are representative of what the literature describes as being mindful. The literature places a large focus on the breath as being the anchor of mindfulness (Hạnh, 1998; J. Miller, 2014; Kabat-Zinn, 2011; Salzberg, 2010). All four 
participants included a focus on breathing throughout their implementation of mindfulness practices in their classrooms. Each participant included some elements of what would be found in a typical MBSR program created by Jon Kabat-Zinn (2003). Megan, Michael, and Leslie included mindful breathing using concrete associations such as smelling a flower or blowing out a candle, while Melissa further expanded this mindful breathing to make connections to how animals would breathe.

The MBSR program that consists of eight weekly sessions for two and a half hours (Kabat-Zinn, 2003) per week would not be feasible to include into the school curriculum nor would be suitable for young children in the primary grades due to the length of each session. However the participants throughout the day incorporated some elements such as mindful movements, awareness activities, and yoga. Mindful movements were represented through yoga and walking. Awareness activities were implemented through the use of acknowledging sounds from a Tibetan singing bowl, awareness of the senses from listening, seeing, and the use of a "feely box." Loving-kindness meditation, which is not found in MBSR, was used by some of the participants. When engaging in a loving-kindness meditation, individuals nurtured feelings towards themselves, loved ones, and all beings in the universe (Salzberg, 2011). Leslie and Michael adapted this type of meditation to include a 'Thank You', 'Kindness', and 'Thought' Circle, as well as a group discussion surrounding words such as 'peace' and 'friendship.'

The use of these types of circles was successful as they were adapted to meet the needs and abilities of young primary students. Each participant was able to make accommodations to their mindfulness practices according to their class size and the various needs of their students. Despite some of the differences and adaptations made in each of the classrooms, it was apparent 
that teachers typically noticed their students to be accepting of mindfulness and observed benefits associated with these practices.

\section{Benefits of Mindfulness in the Classroom}

The findings from this study were supported by the literature about the benefits of participating in a mindfulness-based intervention program for young children. In particular for children between the grades of kindergarten to grade three, there have been many positive effects of mindfulness which include an improved ability to handle classroom demands, increased attention span, and less anxiety (Black \& Fernando, 2014; Napoli et al., 2005; Semple et al., 2015). Since each educator has implemented mindfulness practices on their own, they have been able to observe the benefits and challenges associated with this practice. Similar to the study by Semple et al. (2015), it was found that there was a reduction in challenging behaviours that was a result of developing empathetic and pro-social behaviours, which improved relationships with other children in the classroom. Learning about feelings during mindfulness practice allowed the children to be better equipped to deal with their emotions and how to respond to them.

The two studies by Flook et al. (2010) and Flook et al. (2015) that described an improvement in executive functioning were similar to the findings that were reported. Participants felt that their students were more self-regulated and were better able to solve conflict in the classroom. Teachers also noted decreased instances of behaviours that were associated with anxiety that was similar to other research studies (Anand \& Sharma, 2014; Biegel et al., 2009; Benn et al., 2012; Morone et al., 2012; Van Dam et al., 2014). There were other perceived benefits of mindfulness practices for children in the primary grades that were not discussed in the literature. The findings stated that through practice, there was an overall sense of calmness in the classroom and a greater awareness of classmates. Children were found to have an increased 
awareness of the different senses (sight, sound, touch, smell, taste) and were more detail oriented in their classroom work.

\section{Challenges Associated with Mindfulness in the Classroom}

Some of the literature (Farias \& Wikholm, 2015; Johanson, 2006; Lomas et al., 2015; Lustk et al., 2009; Shapiro \& Carlson, 2009; Sobcsak \& West, 2013) described the challenges associated with mindfulness practices and the adverse effects that may occur. Sobcsak and West (2013) stated that religion might cause a problem when engaging in mindfulness as participants may feel as if this practice is infringing upon their religious beliefs. Their suggestion to ensure that participants are knowledgeable about the practice and concerns addressed can be related to the interviews conducted with participants. The four participants did not express any religious concerns from the parents. As stated, Michael spoke about mindfulness and the practices that he would be using with his students during curriculum night with parents. By informing the parents prior to implementation resulted in parents feeling more comfortable with these practices. Participants did not describe any adverse effects such as uncovering traumatic experiences, avoidance behaviours, depression, anxiety, and anger that were noted in the literature (Farias \& Wikholm, 2015; Lustk et al., 2009; Sobczak \& West, 2013). It could be suggested that adverse effects of mindfulness did not occur due to limited opportunities for in-depth conversations with students in small groups. Young children may not have had the chance to describe their experiences in ways other than through conversation that may elicit adverse responses.

The findings uncovered other challenges such as large class sizes and teacher schedules that were not reflected in the literature. A common theme in successful execution was surrounding the large class sizes. With class sizes of up to 31 children, these teachers found that it would be difficult to facilitate mindfulness practices in large groups. Quite often it would take 
a very long time to initiate one practice, which could be of an issue for a prep teacher, such as Melissa, who has each group of her students for 40 minutes at a time. While Megan and Leslie spoke about the issue of large class sizes, Leslie was fortunate to have an Early Childhood Educator working with her that would allow her to create smaller mindfulness groups.

Melissa described other issues with implementation that was not found in the literature.

She observed the school board was not being configured to facilitate holistic practices and found that she was not working in an environment where she felt safe to take risks and implement new strategies with her students. She stressed the need for more financial support and opportunity for collaboration with other teachers, support staff, and principals in her school board. She also felt as if the leadership did not have positive attitudes towards these new ideas and needed an opportunity to experience mindfulness firsthand. Some of these barriers could be demotivating, especially for new teachers who may be apprehensive about trying new ideas into their classroom. It is imperative that teachers have the support from administration in order to feel comfortable trying new approaches in their teaching practices.

\section{Feasibility of Implementing a Program}

The findings displayed some similarities and differences between what was found in the literature and teachers' experiences in the classroom. The research (Britton et al., 2014; Viafora et al., 2015; Weijer-Bergsma et al., 2014) described the feasibility of implementing a lowintensity mindfulness program into the educational setting. However, there is a lack of literature surrounding feasibility of implementing mindfulness by classroom teachers without guidance, as each of these studies (Britton et al., 2014; Viafora et al., 2015; Weijer-Bergsma et al., 2014) were conducted by researchers who had an allotted time period for implementing mindfulness practices with students. The findings did demonstrate that embedding a low-intensity 
mindfulness program was also feasible in a classroom setting where the teacher has control over daily routines. The ability to implement mindfulness practices throughout the day, such as during circle time or small group activities, demonstrates that it can be successfully integrated in the classroom routine outside of an allotted time for research.

\section{Implications for Practice}

There are some recommendations for teachers to consider when implementing a mindfulness program within their classroom setting. Firstly, it is important to become knowledgeable about the origins of mindfulness found in Buddhism and the importance of selfpractice. In order to integrate this type of program throughout the day, the teacher must have experience practicing him/herself in order to be a role model for the students. In addition to becoming aware of the origins of mindfulness, it is essential that teachers become aware of the possible adverse effects that may be associated with this type of practice. It is important to get to know the children and families in order to determine whether mindfulness is suitable. Through discussion and self-reflection, it is possible that students may bring up thoughts and feelings that have been buried for some time. It is vital to acknowledge these feelings and if required, seek additional guidance in order to support students in needs.

Since students within the classroom have different abilities and experiences, teachers should take the time to experiment with different ways to incorporate mindfulness and determine whether or not certain practices work well. Children may or may not be as responsive depending on their age, interests, and life experiences. By trying different mindfulness practices, which may include mindful breathing, mindful walking, mindful eating, or a loving-kindness meditation, teachers can reflect upon their students' participation and active engagement in practice. 
Teachers can also explore different ways for children to engage in mindfulness practices by integrating an artistic element. Incorporating an arts-based element into mindfulness practices allows young children to participate in practice that is fun and adapted for their needs (Caholic, 2011). For example, during circle time, instead of discussing thoughts or participating in a loving kindness meditation, children can still practice mindfulness in artistic ways such as drawing or through dramatic play. Integrating this artistic element is especially useful for young children who may find it difficult to concentrate or feel apprehensive about participating in small or large group activities (Caholic, 2011).

\section{Limitations to the Study and Directions for Further Research}

Due to the limited number of participants in this study, the findings cannot be generalized to a larger population. This topic would benefit from recruiting participants earlier on in the school year. Since the recruitment occurred towards the end of the school year, it is possible that teachers may have been busy finishing up the year with their students. In addition, including more participants recruited through various means such as additional list serves in the school board would be of value. Opening up the recruitment to different school boards could potentially allow for others who may not be included in the holistic education network list-serve or the mindfulness newsletter list serve used, the opportunity to participate. By expanding the recruitment source, the demographics, gender, and cultural diversity of the participants could be widened as the four participants were all employed in Southern Ontario, were mostly female, had ten years or less of professional teaching experience, and were all visible Caucasians. Extending the study to recruit teachers into the later primary and junior/intermediate grades as well as including families who practice mindfulness could be of value, as it would provide a different perspective of how mindfulness practices are used in the older grades and within a family setting. 
Further research could include interviewing children in classrooms where mindfulness practices are implemented. Children's voices could be heard through interviews and the questions asked could inquire about their thoughts and feelings towards the practices implemented in class and whether or not they have applied mindfulness in their own lives. Making these changes to recruitment measures could further add to the current research on mindfulness practices with children. 


\section{Appendix A: Email Message}

\section{Email message to contacts in Dr. Binder's network:}

Dear

I am currently supervising a graduate student, Stephanie Piotrowski for her master's research paper on mindfulness practices for young children in learning environments. I am aware you are practicing mindfulness with your students. I am able to assist in this process by emailing you and asking you if you are interested in participating in her study. If interested, please email Stephanie at stephanie.piotrowski@ryerson.ca and she will send you a recruitment letter that explains further and if you decide to participate letter of consent. Stephanie will also be able to answer any questions you have.

Kind regards,

Marni Binder 


\title{
Appendix B: Recruitment Letter
}

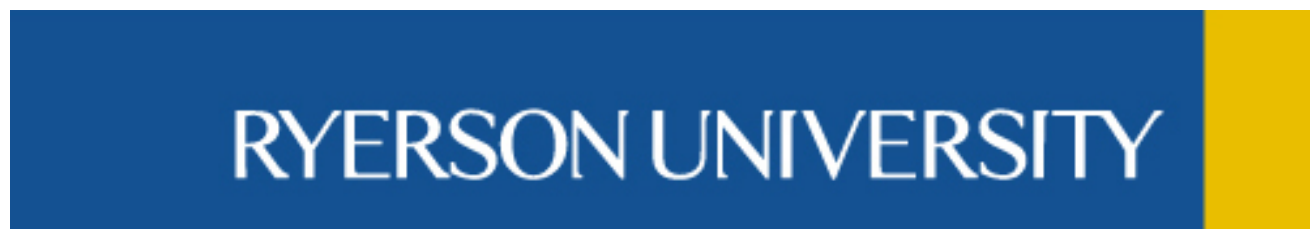

\author{
SCHOOL OF EARLY CHILDHOOD STUDIES \\ FACULTY OF COMMUNITY SERVICES
}

\section{Advertisement for recruitment of study participants}

\section{Are you interested in participating in a study that explores the effects of mindfulness practices with young children?}

My name is Stephanie Piotrowski and I am a student in the Master's of Arts in Early Childhood Studies program at Ryerson University. My work will look at the effects of mindfulness practices with young children in a variety of learning environments.

As a part of a major research paper, I have planned a study project where I would like to interview educators who are using mindfulness practices with children between the ages of 4 to 8 . There will be one interview for approximately 60 minutes. I will collect information through audiotaping and a research journal.

I will ask questions about mindfulness practices in your daily life and when working with children. I would like to hear about your stories and learn about the effects of mindfulness practices with young children in the learning environment you work in.

Through this interview I hope to add to existing literature about mindfulness practices especially when working with young children. I feel that your experiences of using these practices in the educational setting would provide insight into the effects mindfulness has on children.

Participation is voluntary. If you do not participate in the study, it will not affect your relationship with myself, my supervisor Dr. Marni Binder, or Ryerson University.

If you would like more information about this study or how to participate, you may contact me at stephanie.piotrowski@ryerson.ca

Sincerely,

Stephanie Piotrowski

350 Victoria Street, Toronto, Ontario, Canada M5B 2K3

Tel: 416 979-5306 Fax: 416 979-5239 TDD/TTY: 416 979-5138 www.ryerson.ca 


\title{
Appendix C: Consent Letter
}

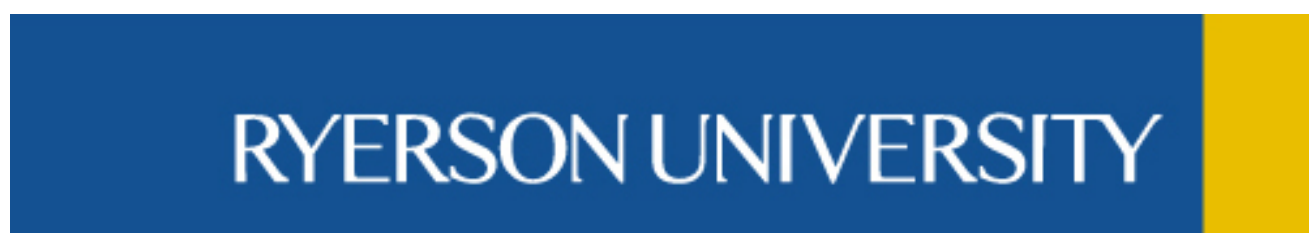

\author{
SCHOOL OF EARLY CHILDHOOD STUDIES \\ FACULTY OF COMMUNITY SERVICES
}

Date:

\section{CONSENT TO PARTICIPATE IN RESEARCH}

Title of Study: Effects of Mindfulness Practices With Young Children in Learning Environments (Working title)

You are being invited to participate in a research study. Please read this Consent Form so that you understand what your participation will involve and ask any necessary questions to be sure you understand.

\section{INVESTIGATOR}

This research study is being conducted by Stephanie Piotrowski, a student in the Masters of Arts in Early Childhood at Ryerson University, Toronto Canada.

If you have any questions or concerns about the research, please feel free to contact:

Stephanie Piotrowski

stephanie.piotrowski@ryerson.ca

\section{PURPOSE OF THE STUDY}

This study will explore the effects of mindfulness practices when working with young children in different learning environments. I am interesting in exploring different educator's experiences facilitating this practice. Through interviewing educators, I will learn more about how mindfulness is practiced with children and the various effects it has.

There will be one interview for approximately 45 to 60 minutes. I will ask questions about mindfulness practices in your daily life and when working with children. I would like to hear about your stories and learn about the effects of mindfulness practices you have observed in the learning environment. What I learn from your interviews will help me to gain an understanding 
of how mindfulness practices influences young children between the ages of 4 to 8 years old. I will be audiotaping the interviews and making notes throughout.

\section{DESCRIPTION OF THE STUDY AND YOUR PARTICIPATION}

If you volunteer to participate in this study, you will be asked to do the following things:

- Participate in one 45-60 minute interview that will be audiotaped in a place of your choice.

\section{Example of Interview Questions}

1. When did you start practicing mindfulness?

2. How would you describe your role in the community?

3. How do you see the role of mindfulness practices with young children?

\section{Information about you}

I will ask for some information about you. For example:

- How long have you been practicing mindfulness with children?

- What settings have you worked with children?

\section{Research Findings}

I will email a transcription of the interview for verification. I will provide you with a copy of the major research paper upon completion.

\section{POTENTIAL RISKS AND DISCOMFORTS}

Potential risks are low. The following is in place to keep risk or any discomforts low.

- You may choose not to answer or skip any questions or discussions you do not wish to take part in.

- You may ask for a break at any time during the interview.

- You are free to stop participating at anytime.

- If you choose to stop participating in the interview, this will not affect the relationship with myself, the School of Early Childhood Studies, or Ryerson University. Any data collected will be destroyed at that time.

POTENTIAL BENEFITS TO PARTICIPANTS AND/OR TO SOCIETY 
This research will be of benefit to you as it offers a chance to share the importance of mindfulness practices and how this contributes to the learning of young children and their overall well-being. It shows the important role you play in your community. It is anticipated that this research study will benefit the discussion of mindfulness practices as an important tool for young children in learning environments.

\section{PAYMENT FOR PARTICIPATION}

No payment is being offered to take part in the study.

\section{CONFIDENTIALITY}

Myself and my supervisor, Dr. Marni Binder, will be the only one who has access to all data collected. All data (audio-recordings, transcripts) will be stored on a secure password protected computer in Dr. Binder's office at Ryerson University. The data will be kept for one year after completion of the major research paper and then destroyed.

As a participant, you have the right to hear the interviews and see the transcriptions.

\section{VOLUNTARY PARTICIPATION AND WITHDRAWAL}

Participation in this study is voluntary. You can choose whether to be in this study or not. If you volunteer to be in this study, you may withdraw at any time without consequences of any kind. If you choose to withdraw from this study you may also choose to withdraw your data from the study. You may also choose not to answer any question(s) and still remain in the study. Your choice of whether or not to participate will not influence your future relations with myself, Dr. Marni Binder, or Ryerson University.

\section{QUESTIONS ABOUT THE STUDY}

If you have any questions about the research now, please ask. If you have questions later about the research, you may contact me at:

Stephanie Piotrowski

stephanie.piotrowski@ryerson.ca

This study has been reviewed by the Ryerson University Research Ethics Board. If you have questions regarding your rights as a research participant in this study, please contact:

Research Ethics Board

Office of the Vice President, Research and Innovation

Ryerson University

350 Victoria Street

Toronto, Ontario M5B 2K3

416-979-5042 


\section{SIGNATURE OF RESEARCH PARTICIPANT}

Your signature below indicates that you have read the information in this agreement and have had a chance to ask any questions you have about the study Effects of Mindfulness Practices With Young Children in Learning Environments as described herein. Your questions have been answered to your satisfaction, and you agree to participate in this study. You have been given a copy of this form.

Name of Participant (please print)

Signature of Participant

Please also check the appropriate box for the following:

I consent to being audio-recorded.

Signature of Participant 


\section{Appendix D: Interview Guide}

\section{Interview Guide}

Date:

Pseudonym:

- Please tell me about your work with children. How long have you been working in this learning environment? What other teaching experiences have you had?

- When did you start practicing mindfulness yourself?

- How did you learn about mindfulness?

- How do you see the role of mindfulness in the lives of young children?

- Please explain your work with children using mindfulness practices.

- Which types of mindfulness practices do you frequently use with young children?

- Which mindfulness practices have children responded well to?

- Which mindfulness practices have children not responded well to?

- Have you noticed any short-term effects of mindfulness?

- Have you noticed any long-term effects of mindfulness?

- Have you seen any negative effects associated with mindfulness practices?

- Do the children you work with enjoy participating in mindfulness?

- How do parents respond to this type of practice?

- Have parents talked to you about any effects they have noticed from their child as a participant in mindfulness?

- How will you continue to support mindfulness practices in your learning environment?

- Do you have any last comments 


\section{References}

Alleva, J., Roelofs, J., Voncken, M., Meevissen, Y., \& Alberts, H. (2014). On the relation between mindfulness and depressive symptoms: Rumination as a possible mediator. Mindfulness, 5(1), 72-79.

Amerijcjx, G., \& Humblet, P. C. (2014). Child well-being: What does it mean? Children \& Society, 28(5), 404-415.

Anand, U., \& Sharma, M. P. (2014). Effectiveness of a mindfulness-based stress reduction program on stress and well-being in adolescents in a school setting. Indian Journal of Positive Psychology, 5(1), 17-22.

Baer (2006). Mindfulness-based treatment approaches: Clinician's guide to evidence base and applications. London, UK: Elsevier.

Beauchemin, J., Hutchins, T. L., Patterson, F. (2008). Mindfulness meditation may lessen anxiety, promote social skills, and improve academic performance among adolescents with learning disabilities. Complementary Health Practice Review, 13(1), 34-45.

Benn, R., Akiva, T., Arel, S., \& Roeser, R. W. (2012). Mindfulness training effects for parents and educators of children with special needs. Developmental Psychology, 48(5), 14761487.

Biegel, G. M., Brown, K. W., Shapiro, S. L., \& Schubert, C. M. (2009). Mindfulness-based stress reduction for the treatment of adolescent psychiatric outpatients: A randomized clinical trial. Journal of Consulting and Clinical Psychology, 77(5), 855-866.

Bishop, S. R. (2002). What do we really know about Mindfulness-based Stress Reduction? Psychosomatic Medicine, 64(1), 71-84. 
Black, D. S., \& Fernando, R. (2014). Mindfulness training and classroom behavior among lowerincome and ethnic minority elementary school children. Journal of Child and Family Studies, 23(7), 1242-1246.

Braun, V., \& Clarke, V. (2006). Using thematic analysis in psychology. Qualitative Research in Psychology, 3(2), 77-101.

Braun, V., \& Clarke, V. (2014). What can "thematic analysis" offer health and wellbeing researchers? International Journal of Qualitative Studies on Health and Well-Being, 9, 12.

Britton, W. B., Lepp, N. E., Niles, H. F., Rocha, T., Fisher, N. E., \& Gold, J. S. (2014). A randomized controlled pilot trial of classroom-based mindfulness meditation compared to an active control condition in sixth-grade children. Journal of School Psychology, 52(3), 263-278.

Caholic, D. A. (2011). Exploring the feasibility and benefits of arts-based mindfulness-based practices with young people in need: Aiming to improve aspects of self-awareness and resilience. Child \& Youth Care Forum, 40(4), 303-317.

Campbell, L. H. (2011). Holistic art education: A transformative approach to teaching art. Art Education, 64(2), 18-24.

Capel, C. M. (2012). Mindlessness/mindfulness, classroom practices and quality of early childhood education. International Journal of Quality \& Reliability Management, 29(6), 666-680.

Coffey, K. A., Hartman, M., \& Fredrickson, B. L. (2010). Deconstructing mindfulness and constructing mental health: Understanding mindfulness and its mechanisms of action. Mindfulness, (1), 235-253. 
Crane, R. S., Kuyken, W., Hastings, R. P., Rothwell, N., \& Williams, J. M. G. (2010). Training teachers to deliver mindfulness-based interventions: Learning from the UK experience. Mindfulness, $1(2), 74-86$.

Creswell, J. W. (2008). Educational research: planning, conducting, and evaluating quantitative and qualitative research. Upper Saddle River, NJ: Pearson Education, Inc.

Creswell, J. W. (2014). Research design: Qualitative, quantitative, and mixed methods approaches. Thousand Oaks, California: SAGE Publications, Inc.

Erisman, S. M., \& Roemer, L. (2012). A preliminary investigation of the process of mindfulness. Mindfulness, 3(1), 30-43.

Farias, M., \& Wikholm, C. (2015). The Buddha pill. London, England: Watkins Media Limited.

Felver, J. C., Frank, J. L., McEachern, A. D. (2014). Effectiveness, acceptability, and feasibility of the Soles of the Feet mindfulness-based intervention with elementary school students. Mindfulness, 5(5), 589-597.

Flook, L., Goldberg, S. B., Pinger, L., Bonus, K., Davidson, R. J. (2013). Mindfulness for teachers: A pilot study to assess effects on stress, burnout, and teaching efficacy. Mind, Brain, and Education, 7(3), 182-195.

Flook, L., Goldberg, S. B., Pinger, L., \& Davidson, R. J. (2015). Promoting prosocial behavior and self-regulatory skills in preschool children through a mindfulness-based kindness curriculum. Developmental Psychology, 51(1), 44-51.

Flook, L., Smalley, S. L., Kitil, M. J., Galla, B. M., Kaiser-Greenland, S., Locke, J., Ishijima, E., \& Kasari, C. (2010). Effects of mindful awareness practices on executive functions in elementary school children. Journal of Applied School Psychology, 26(1), 70-95. 
Frank, J. L., Reibel, D., Broderick, P., Cantrell, T., \& Metz, S. (2015). The effectiveness of Mindfulness-Based Stress Reduction on educator stress and well-being: Results from a pilot study. Mindfulness, 6(2), 208-216.

Fredrickson, B. L., Cohn, M. A., Coffey, K. A., Pek, J., \& Finkel, S. M. (2008). Open hearts build lives: Positive emotions, induced through loving-kindness meditation, build consequential personal resources. Journal of Personality and Social Psychology, 95(5), 1045-1062.

Gold, E., Smith, A., Hopper, I., Herne, D., Tansey, G., \& Hulland, C. (2010). Mindfulness-Based Stress Reduction (MBSR) for primary school teachers. Journal of Child and Family Studies, 192(2), 184-189.

Hạnh, T. N. (1987). The miracle of mindfulness: An introduction to the practice of meditation. Boston, MA: Beacon Press.

Hạnh, T. N. (1992). Peace is every step: The path of mindfulness in everyday life. New York, NY: Bantam Books.

Hạnh, T. N. (1998). The heart of the Buddha's teaching. Berkeley, CA: Parallax Press.

Holzel, B. K., Carmody, J., Vangel, M., Congleton, C., Yerramsetti, S. M., Gard, T., \& Lazar, S. W. (2011). Mindfulness practice leads to increases in regional brain gray matter density. Psychiatry Research: Neuroimaging, 191(1), 36-43.

Hunsinger, M., Livingston, R., \& Isbell, L. (2013). The impact of loving-kindness meditation on affective learning and cognitive control. Mindfulness, 4(3), 275-280.

Johanson, G. (2006). A survey of the use of mindfulness in psychotherapy. Annals of the American Psychotherapy Association, 9(2), 15-24. 
Kabat-Zinn, J. (2003). Mindfulness-based interventions in context: Past, present, and future. Clinical Psychology: Science and Practice, 10(2), 144-156.

Kabat-Zinn, J. (2005). Coming to our senses. New York, NY: Hyperion.

Kabat-Zinn, J. (2011). Mindfulness for beginners: Reclaiming the present moment - and your life. Boulder, CO: Sounds True, Inc.

Kabat-Zinn, J. (2013). Full catastrophe living: Using the wisdom of your body and mind to face stress, pain, and illness. New York, NY: Bantam Books.

King, N., \& Horrocks, C. (2010). Interviews in qualitative research. London, England: SAGE Publications Ltd.

Kornfield, J. (2007). Modern Buddhist masters. Kandy, Sri Lanka: Buddhist Publication Society. Kornfield, J. (2008). Meditation for beginners. Louisville, CO: Sounds True, Inc.

Kornfield, J. (2012). Bringing home the dharma: Awakening right where you are. Boston, MA: Shambhala Publications, Inc.

Kreitzer, M. (2012). Spirituality and well-being: Focusing on what matters. Western Journal of Nursing Research, 34(6), 707-711.

Leung, M., Chan, C. C. H., Yin, J., Lee, C., So, J., and Lee, T. M. C. (2013). Increased gray matter volume in the right angular and posterior parahippocampal gyri in loving-kindness meditators. Social Cognitive And Affective Neuroscience, 8(1), 34-39.

Leppma, M. (2012). Loving-kindness meditation and counseling. Journal of Mental Health Counseling, 34(3), 197-205.

Liehr, P., \& Diaz, N. (2010). A pilot study examining the effect of mindfulness on depression and anxiety for minority children. Archives of Psychiatric Nursing, 24(1), 69-71. 
Lomas, T., Cartwright, T., Edginton, T., \& Ridge, D. (2015). A qualitative analysis of experiential challenges associated with meditation practices. Mindfulness, 6(4), 848-860.

Lustk, M. K. B., Chawla, N., Nolan, R. S., \& Marlatt, G. A. (2009). Mindfulness meditation research: Issues of participant screening, safety procedures, and researcher training. ADVANCES, 24(1), 20-30.

Mahmoudi, S., Jafari, E., Nasrabadi, H. A., \& Liaghatdar, M. J. (2012). Holistic education: An approach for 21 Century. International Education Studies, 5(2), 178-186.

McCown, D., Rebel, D., \& Micozzi, M. S. (2010). Teaching mindfulness: A practical guide for clinicians and educators. New York, NY: Springer.

Mendelson, T., Dariotis, J. K., Gould, L. F., Smith, A. S. R., Smith, A. A., Gonzalez, A. A., \& Greenberg, M. T. (2013). Implementing mindfulness and yoga in urban schools: A community-academic partnership. Journal of Children's Services, 8(4), 276-291.

Miller, J. P. (2006). Educating for wisdom and compassion: Creating conditions for timeless learning. Thousand Oaks, California: Corwin Press.

Miller, J. P. (2007). The holistic curriculum (2nd ed.). Toronto, Canada: University of Toronto Press Inc.

Miller, J. P. (2014). The Contemplative Practitioner: Meditation in Education and the Workforce. Toronto, Canada: University of Toronto Press.

Miller, R. (1991). Educating the true self: Spiritual roots of the Holistic worldview. Journal of Humanistic Psychology, 31(4), 53-67.

Miller, R. (2000). Beyond reductionism: The emerging holistic paradigm in education. The Humanistic Psychologist, 28(1-3), 382-393. 
Morone, N. E., Lynch, C. P., Losasso, V. J., Liebe, K., \& Greco, C. M. (2012). Mindfulness to reduce psychosocial stress. Mindfulness, 3(1), 22-29.

Napoli, M., Krech, P. R., \& Holley, L. C. (2005). Mindfulness training for elementary school students. Journal of Applied School Psychology, 21(1), 99-125.

Olson, K. (2011). Essentials of qualitative interviewing. Walnut Creek, CA: Left Coast Press, Inc.

Ott, M. J. (2004). Mindfulness meditation: A path of transformation \& healing. Journal of Psychosocial Nursing and Mental Health Services, 42(7), 22-29.

Rempel, K. D. (2012). Mindfulness for children and youth: A review of the literature with an argument for school-based implementation. Canadian Journal of Counselling and Psychotherapy, 46(3), 201-220.

Rotne, N. F., \& Rotne, D. F. (2013). Everybody present. Berkeley, CA: Parallax Press.

Salzberg, S. (1997). A heart as wide as the world: Stories on the path of lovingkindness. Boston, MA: Shambhala Publications, Inc.

Salzberg, S. (2008). Lovingkindness. Boston, MA: Shambhala Publications, Inc.

Salzberg, S. (2010). Real happiness: The power of meditation. New York, NY: Workman Publishing.

Salzberg, S. (2011). Mindfulness and loving-kindness. Contemporary Buddhism, 12(1), 177-182. Sandelowski, M. (2000). Whatever happened to qualitative description? Research in Nursing \& Health, 23(4), 334-340.

Schonert-Reichl, K. A., \& Lawlor, M. S. (2010). The effects of a mindfulness-based education program on pre- and early adolescents' well-being and social and emotional competence. Mindfulness, 1(3), 137-151. 
Seale, C., \& Silverman, D. (1997). Ensuring rigour in qualitative research. The European Journal of Public Health, 7(4), 379-384.

Semple, R. J., Reid, E. F. G., \& Miller, L. (2005). Treating anxiety with mindfulness: An open trial of mindfulness training for anxious children. Journal of Cognitive Psychotherapy, 19(4), 379-392.

Shapiro, S. L., \& Carlson, L. E. (2009). Mindfulness-informed therapy. In S. L. Shapiro \& L. E. Carlson (Eds.), The art and science of mindfulness: Integrating mindfulness into psychology and the helping professions (pp. 31-43). Washington, DC: American Psychological Association.

Shonin, E., \& Van Gordon, W. (2015). Practical recommendations for teaching mindfulness effectively. Mindfulness, 6(4), 952-955.

Sobczak, L. R., \& West, L. M. (2013). Clinical considerations in using mindfulness- and acceptance-based approaches with diverse populations: Addressing challenges in service delivery in diverse community settings. Cognitive and Behavioral Practice, 20(1), 13-22.

Taggart, G. (2001). Nurturing spirituality: A rationale for holistic education. International Journal of Children's Spirituality, 6(3), 325-339.

Uhrmacher, P. B. (1995). Uncommon schooling: A historical look at Rudolf Steiner, Anthroposophy, and Waldorf education. Curriculum Inquiry, 25(4), 381-406.

Van Aalderen, J. R., Breukers, W. J., Reuzel, R. P. B., \& Speckens, A. E. M. (2014). The role of the teacher in mindfulness-based approaches: A qualitative study. Mindfulness, 5(2), 170178. 
Van Dam, N. T., Hobkirk, A. L., Sheppard, S. C., Aviles-Andrews, R., \& Earleywine, M. (2014). How does mindfulness reduce anxiety, depression, and stress? An exploratory examination of change processes in wait-list controlled mindfulness meditation training. Mindfulness, 5(5), 574-588.

Viafora, D. P., Mathiesen, S. G., \& Unsworth, S. J. (2015). Teaching mindfulness to middle school students and homeless youth in school classrooms. Journal of Child and Family Studies, 24(5), 1179-1191.

Waddell, C. (2007). Improving the mental health of young children: A discussion paper prepared for the British Columbia Healthy Child Development Alliance. Retrieved from http://www.firstcallbc.org/pdfs/Communities/4-alliance.pdf

Weijer-Bergsma, van de, E., Langenberg, G., Brandmsa, R., Oort, F. J., Bogels, S. M. (2014). The effectiveness of a school-based mindfulness training as a program to prevent stress in elementary school children. Mindfulness, 5(3), 238-248. 